\title{
Marchantia polymorpha L. ethanol extract induces apoptosis in hepatocellular carcinoma cells via intrinsic- and endoplasmic reticulum stress-associated pathways
}

Fangfang Zhou ${ }^{\dagger}$, Adila Aipire ${ }^{\dagger}$, Lijie Xia, Xierenguli Halike, Pengfei Yuan, Mamtimin Sulayman, Weilan Wang ${ }^{*}\left(\mathbb{D}\right.$ and Jinyao $\mathrm{Li}^{*}$

\begin{abstract}
Background: Marchantia polymorpha L. is a kind of Chinese herbal medicine and has various biological activities including antioxidant and antifungal. However, it is not clear about the antitumor effect and mechanism of M. polymorpha. We prepared M. polymorpha ethanol extract (MPEE) and investigated its antitumor effect on hepatocellular carcinoma cells both in vitro and in vivo.

Methods: The viability of hepatocellular carcinoma cells was detected by MTT assay. The distribution of cell cycle was analyzed by propidium iodide (PI) staining. The morphology of nuclei was observed by Hoechst 33258 staining. Apoptosis was detected by Annexin V/PI staining. JC-1 fluorescent probe and DCFH-DA were used to detect the mitochondrial membrane potential $(\triangle \psi M)$ and the level of reactive oxygen species (ROS), respectively. Caspase inhibitors were used to test the function of caspase in the induction of apoptosis. Quantitative real time polymerase chain reaction (qRT-PCR) and Western blot were used to evaluate the levels of mRNA and protein, respectively. Differentially expressed genes and signaling pathways were identified by transcriptome analysis. The $\mathrm{H} 22$ tumor mouse model was used to detect the antitumor effect of the extract.

Results: MPEE significantly suppressed the migration and growth of BEL-7404, HepG2 and H22 cells in a dose- and time-dependent manner through induction of apoptosis characterized by chromosomal condensation and cell cycle arrest at G0/G1 and G2/M phases. MPEE induced mitochondria-dependent apoptosis via upregulation of Bax and downregulation of $\mathrm{BCl}-2$ to reduce mitochondrial membrane potential and increase the release of cytochrome $c$. The levels of cleaved caspase-8 and -9 were significantly increased, which sequentially activated caspase-3 to cleave PARP. We further found that MPEE significantly increased ROS production and activated endoplasmic reticulum (ER) stress associated-apoptotic signaling pathway. Moreover, MPEE significantly inhibited H22 tumor growth in mouse model and improved the survival of tumor mice.
\end{abstract}

Conclusion: These results suggested that MPEE suppressed hepatocellular carcinoma cell growth through induction of apoptosis via intrinsic- and ER stress-associated pathways.

\footnotetext{
*Correspondence: wwlbiology@163.com; ljyxju@xju.edu.cn

${ }^{\dagger}$ Fangfang Zhou and Adila Aipire contributed equally to this work

Xinjiang Key Laboratory of Biological Resources and Genetic

Engineering, College of Life Science and Technology, Xinjiang University,

Urumqi 830046, China
}

(c) The Author(s) 2021. Open Access This article is licensed under a Creative Commons Attribution 4.0 International License, which permits use, sharing, adaptation, distribution and reproduction in any medium or format, as long as you give appropriate credit to the original author(s) and the source, provide a link to the Creative Commons licence, and indicate if changes were made. The images or other third party material in this article are included in the article's Creative Commons licence, unless indicated otherwise in a credit line to the material. If material is not included in the article's Creative Commons licence and your intended use is not permitted by statutory regulation or exceeds the permitted use, you will need to obtain permission directly from the copyright holder. To view a copy of this licence, visit http://creativecommons.org/licenses/by/4.0/. The Creative Commons Public Domain Dedication waiver (http://creativeco mmons.org/publicdomain/zero/1.0/) applies to the data made available in this article, unless otherwise stated in a credit line to the data. 
Keywords: Marchantia polymorpha L., Hepatocellular carcinoma, Apoptosis, Signaling pathway, Tumor mouse model

\section{Introduction}

Liver cancer is the sixth most commonly diagnosed cancer and the fourth leading cause of cancer death worldwide in 2018, with about 841,000 new cases and 782,000 deaths annually [1]. About $90 \%$ of primary liver cancers are hepatocellular carcinoma (HCC) that causes a major global health problem [2]. The pattern of HCC occurrence shows a large geographical imbalance, with the highest incidence rates in East Asia (more than $50 \%$ of the cases occurring in China) [3]. Due to lack of early screening methods, most of patients with HCC were at the advanced stage when they were diagnosed, which led to the poor prognosis. Although a multitude of chemotherapy and targeted therapy agents have been evaluated for the treatment of advanced HCC, such as sorafenib [4, 5], regorafenib [6], and lenvatinib [7], the overall survival benefits are modest. Therefore, the innovative drugs and approaches need to be developed.

Natural products with various structures and biological activities are the treasure of resources for the development of new drugs for cancer treatment. Recently, bryophytes attract lots of interests because they have various biological activities. Many active components including acetogenins, terpenoids and bisbibenzyls have been identified from bryophytes [8] and show different activities, such as antifungal [9], antibacterial [10, 11], antiviral [12], anti-inflammatory [13, 14] and antioxidative $[15,16]$. Marchantia polymorpha L., a kind of traditional Chinese medicine, distributes worldwide and exhibits antioxidant and antifungal functions [16, 17]. It has been reported that Marchantin A from $M$. polymorpha can inhibit the growth of human MCF-7 breast cancer cells, and increase the levels of cleaved caspase-8, cleaved caspase-3, cleaved caspase-9, and cleaved poly (ADP ribose) polymerase (PARP) $[18,19]$. Riccardin D from $M$. polymorpha can be used to treat lung cancer as a DNA topo II inhibitor [20]. However, few research has been done on the anti-hepatoma effect of M. polymorpha.

In this study, we prepared M. polymorpha ethanol extract (MPEE) and investigated its antitumor effect and mechanism on HCC. We found that MPEE significantly inhibited the growth of HCC cells including BEL-7404, HepG2 and H22 cells through induction of intrinsic- and endoplasmic reticulum (ER) stress-associated apoptosis.

\section{Materials and methods}

Measurement of flavonoids and polysaccharides in MPEE

$M$. polymorpha was collected from Altay in Xinjiang Uygur Autonomous Region, China. MPEE was prepared according to our previous procedure [21]. Specifically, $100 \mathrm{~g}$ powders of $M$. polymorpha were extracted three times using $2 \mathrm{~L}$ of $100 \%$ ethanol. After centrifugation at $6000 \mathrm{rpm}$ for $15 \mathrm{~min}$, the supernatant was evaporated and freeze-dried using a Freezone 2.5 instrument (Labconco, USA). MPEE was dissolved in DMSO and the contents of flavonoids and polysaccharides were detected according to previous description [22].

\section{Characterization and quantification of MPEE by LC-QTOF-MS/MS}

$50 \mathrm{mg}$ of MPEE were applied to extraction procedure, and extracted with $800 \mu \mathrm{L}$ of methanol included internal standard ( $2.8 \mathrm{mg} / \mathrm{mL}$, DL-o-Chlorophenylalanine). And all samples were grinded to fine powder using Grinding Mill at $65 \mathrm{~Hz}$ for $90 \mathrm{~s}$. Then the samples were ultrasonicated for $30 \mathrm{~min}$, by $40 \mathrm{kHz}$ and let stand for $1 \mathrm{~h}$ at $-20{ }^{\circ} \mathrm{C}$. The samples were centrifuged at $12,000 \mathrm{rpm}$ and $4{ }^{\circ} \mathrm{C}$ for $15 \mathrm{~min} .200 \mu \mathrm{L}$ of supernatant was transferred to vial for LC-MS analysis.

Phytochemical characterization of MPEE was conducted using a quadrupole time-of-flight mass spectrometer (Agilent, 1290 Infinity LC, 6530 UHD and Accurate-Mass Q-TOF/MS), which was coupled with an ultraperformance liquid chromatography system (Waters ACQUITY UPLC, Waters Corp., Milford, MA, USA). Chromatographic separation was achieved using an ODS C18 analytical column $(2.5 \mu \mathrm{m} \times 210 \mathrm{~mm}$, Waters ACQUITY UPLC@HSS T3). MS conditions were as follows: the scan range was set at $\mathrm{m} / z 100$ 1000 . The capillary voltage was $4000 \mathrm{~V}$ in positive mode and $3.5 \mathrm{kV}$ in negative mode, the drying gas flow was $11 \mathrm{~L} / \mathrm{min}$ and the temperature was $350{ }^{\circ} \mathrm{C}$. The nebulizer pressure was set to $45 \mathrm{psi}$, the fragmentor voltage was set to $120 \mathrm{~V}$ and the skimmer voltage was set to $60 \mathrm{~V}$. The column was kept at $40{ }^{\circ} \mathrm{C}$, and the flow rate was $0.4 \mathrm{~mL} / \mathrm{min}$. The mobile phase solutions consisted of (A) formic acid (0.1\%) and (B) acetonitrile: $0.1 \%$ formic acid $(1: 1, v / v)$. The gradient program was as follows: $0-2$ min, $5 \%$ B; $2-13$ min, $5 \%$ B; $13-16$ min, $95 \%$ B; 16 min, $95 \%$ B. All samples were kept at $4{ }^{\circ} \mathrm{C}$ during the analysis. The injection volume was $4 \mu \mathrm{L}$. 
The data was performed feature extraction and preprocessed with XCMS in R software, and then normalized and edited into two-dimensional data matrix by Excel 2010 software, including Retention time (RT), Mass-to-charge ratio (MZ), Observations (samples) and peak intensity.

\section{Animals and ethics statement}

Kunming male mice aged 6-8 weeks were housed in a temperature-controlled, light-cycled animal facility of Xinjiang University. These animal studies were authorized by the Committee on the Ethics of Animal Experiments of Xinjiang Key Laboratory of Biological Resources and Genetic Engineering (BRGE-AE001) and carried out in strict accordance with the guide of the Animal Care and Use Committee of College of Life Science and Technology, Xinjiang University. All surgery was performed under sodium pentobarbital anesthesia, and all efforts were made to minimize suffering.

\section{Cell lines and cell culture}

The murine HCC H22 cells, human HCC HepG2 and BEL-7404 cells and the mouse liver NCTC1469 cells were obtained from the Xinjiang Key Laboratory of Biological Resources and Genetic Engineering, Xinjiang University (Urumqi, Xinjiang, China). RPMI 1640 medium (Gibco) was used to culture H22 and BEL-7404 cells, and Dulbecco's Modified Eagle medium (Gibco) was used to culture HepG2 and NCTC1469 cells. These media were supplemented with $10 \%$ heat-inactivated fetal bovine serum (MRC), 1\% L-glutamine (100 mM), $100 \mathrm{U} / \mathrm{mL}$ penicillin and $100 \mu \mathrm{g} / \mathrm{mL}$ streptomycin. All cells were incubated at $37^{\circ} \mathrm{C}$ in a humidified atmosphere of $5 \% \mathrm{CO}_{2}$.

\section{MTT assay and cell morphology observation}

The inhibitory effects of MPEE on the growth of H22, HepG2, BEL-7404 and NCTC1469 cells were measured by MTT [3-(4,5-dimethyl-2-thiazolyl)-2,5-diphenyl-2- $H$ tetrazolium bromide] (Sigma, MO, USA) assay according to our previous description [21]. Briefly, H22, HepG2, BEL-7404 and NCTC1469 cells at the density of $5 \times 10^{4}$ cells $/ \mathrm{mL}$ were seeded in 96 -well plates and cultured overnight. Cells were treated with different concentrations $(0$, 25, 50, 70, 100 or $200 \mu \mathrm{g} / \mathrm{mL}$ ) of MPEE for $24 \mathrm{~h}$ or $48 \mathrm{~h}$. DMSO $(0.6 \%)$ and cisplatin $(30 \mu \mathrm{g} / \mathrm{mL})$ were used as negative or positive controls, respectively. Six wells were repeated for each treatment. Splenocytes $\left(1 \times 10^{6}\right.$ cells/ $\mathrm{mL}$ ) from C57BL/6 mice were seeded in 96-well plates and treated with different concentrations of MPEE for $24 \mathrm{~h}$ and $48 \mathrm{~h}$. The relative cell viability was determined as: Cell viability $(\%)=\left(O D_{\text {treated }} / O D_{\text {untreated }}\right) \times 100 \%$.
After treatment with MPEE for $24 \mathrm{~h}$ and $48 \mathrm{~h}$, the morphology of H22 cells was observed by inverted fluorescence microscope (Nikon Eclipse Ti-E, Japan).

\section{Detection of cell cycle}

$\mathrm{H} 22$ cells were inoculated in $60 \mathrm{~mm}$ culture dishes at the density of $5 \times 10^{4}$ cells $/ \mathrm{mL}$ and treated with different concentrations of MPEE for $24 \mathrm{~h}$. Cells were harvested and fixed with $70 \%$ ethanol at $4{ }^{\circ} \mathrm{C}$ overnight. After washing with cold PBS, cells were stained with propidium iodide (PI) as described [23]. Samples were analyzed by flow cytometry (BD FACSCalibur, CA, USA) and the cell cycle distribution was analyzed using ModFit LT 3.0 software.

\section{Analysis of cell apoptosis}

H22, BEL-7404 and HepG2 cells were treated with different concentrations of MPEE for $24 \mathrm{~h}$ and stained with apoptosis detection kit (YEASEN, China) according to the manufacturer's instructions. DMSO and cisplatin were used as negative and positive controls, respectively. For the inhibitor experiment, $\mathrm{H} 22$ cells were pretreated with $15 \mu \mathrm{M}$ Z-VAD-FMK and $20 \mu \mathrm{M}$ Ac-DEVD-CHO (Beyotime, China) for $2 \mathrm{~h}$, then treated with MPEE for $24 \mathrm{~h}$. Samples were analyzed by flow cytometry.

\section{Hoechst 33258, JC-1 and DCFH-DA staining}

$\mathrm{H} 22$ cells were seeded in 6-well plate at the density of $5 \times 10^{4}$ cells $/ \mathrm{mL}$. After $60 \% \sim 70 \%$ confluence, the cells were treated with MPEE for $24 \mathrm{~h}$. The cells were collected and fixed with $4 \%$ ice-cold Paraformaldehyde at $4{ }^{\circ} \mathrm{C}$ for 10 min. After washing with PBS, H22 cells were stained with Hoechst 33258, JC-1 dye or 2,7 dichlorodihydrofluoresc-ein diacetate (DCFH-DA) (Beyotime, China) as previously described [23]. Samples were observed by an inverted fluorescence microscopy (Nikon, Japan) or analyzed by flow cytometry.

\section{Migration in vitro}

The migration of $\mathrm{H} 22$ cells in vitro was tested by wound healing assay as described [24]. H22 cells $\left(2.5 \times 10^{4} /\right.$ well $)$ were seeded in a 24-well plate. A vertical wound with uniform size was scratched through the center of each well using a $200 \mu \mathrm{L}$ pipette tip. After treatment with MPEE for $24 \mathrm{~h}$ and $48 \mathrm{~h}$, the average distances of cell migration were analyzed by Image J.

\section{Western blot}

The antibodies against caspase-9, Bax, Bcl-2, PERK, eIF2 $\alpha$ and ATF6, the phosphorylation antibodies of PERK and eIF2 $\alpha$, anti-mouse IgG-HRP and anti-rabbit IgG-HRP were purchased from BBI Life Sciences (Shanghai, China). The antibodies against caspase-3, caspase- 8 , PARP, cytochrome $c$ and $\beta$-actin were obtained from Cell 
Signaling Technology (Danvers, MA, USA). The antibodies against $\mathrm{CHOP}$, cyclinB1, cdk2 and cyclin D1were bought from Beyotime (Shanghai, China).

After treatment with MPEE for $24 \mathrm{~h}$, total protein of H22 cells was isolated by RIPA Lysis Buffer (Beijing ComWin Biotech Co., Ltd) and the protein concentration was detected by the bicinchoninic acid assay kit (Thermo Fisher Scientific, USA) according to the manufacturer's instructions. Equal amount of proteins were separated on $12 \%$ SDS-PAGE and then transferred onto PVDF membrane. The membrane was blocked with TBST buffer (20 mmol/L Tris- $\mathrm{HCl}, 150 \mathrm{mmol} / \mathrm{L} \mathrm{NaCl}, 0.05 \%$ Tween 20) contained $5 \%$ skim milk for $1 \mathrm{~h}$ at room temperature, and incubated with primary antibodies overnight at $4{ }^{\circ} \mathrm{C}$ on a gentle shaker. After washing with TBST buffer three times, the membrane was incubated with secondary antibodies for $2 \mathrm{~h}$. The target proteins were visualized using a commercial ECL kit (Beyotime).

\section{Quantitative RT-PCR (qRT-PCR)}

H22 cells were treated with MPEE for $24 \mathrm{~h}$ and the total RNA was extracted by TRIzol reagent (Invitrogen, Carlsbad, CA, USA) according to the manufacturer's protocol. Reverse transcription and quantitative PCR were carried out using reverse transcriptase M-MLV (Takara, China) and TransStart Tip Green qPCR SuperMix Kit (TransGen Biotech, China), respectively. The gene-specific primers were shown in Table 1.

\section{Tumor mouse study}

Kunming male mice were subcutaneously injected with $\mathrm{H} 22$ cells $\left(1 \times 10^{6}\right.$ cells/mice $)$ into the right flank and randomly divided into 5 groups (8 mice/group). After 6 days, tumor mice were intraperitoneally treated with MPEE (50 mg/kg or $100 \mathrm{mg} / \mathrm{kg}$ in $0.1 \mathrm{~mL}$ DMSO) every two days for 10 times. Cisplatin $(5 \mathrm{mg} / \mathrm{kg})$ was intraperitoneally injected every three days for 7 times and $0.1 \mathrm{~mL}$ PBS was intraperitoneally injected every two days for 10 times, which were used as positive and negative controls, respectively. Tumor sizes were measured using calipers and calculated according to the following formula: tumor volume $\left(\mathrm{mm}^{3}\right)=\left(\right.$ length $\times$ width $\left.^{2}\right) / 2$. On day 57, the survival rates of tumor mice in each group were calculated with Prism 5.

Table 1 The gene-specific primers

\begin{tabular}{|c|c|c|}
\hline Gene & Primer sequences $\left(5^{\prime}-3^{\prime}\right)$ & \\
\hline GAPDH & F: AGCCTCGTCCCGTAGACA & R: CTCGCTCCTGGAAGATGG \\
\hline Srp72 & F: GAGGGGTCGACATTGCTCTC & R: GCCAGTTAAAGACCTCCCCC \\
\hline Srp14 & F: GCAAACCAGCACAGTGACAG & R: ACAACTAGCCCAAGCCCATC \\
\hline Srprb & F:TCAGCTCCTGTTGTGTCACC & R: ATGCAGCGATCTGTAGGCTC \\
\hline Srpr & F: AGAGCCTTGGCTGACCATTC & $\mathrm{R}: \mathrm{GCCAGTACCCACAAAGACGA}$ \\
\hline $\operatorname{Srp68}$ & F: CCAAACAAGCCAACCTCGTG & R:TGCCCTTGATGTAGCCTGTG \\
\hline Srp19 & F:TGCTCAGCAGTTGGACTGAAT & R:TTGCTGAAGACTTGGGTCGG \\
\hline Wfs 1 & F: GGAAACTAACATGGCCCGGA & R:TCCAATCGCCCAGGAAGAAC \\
\hline Atf6 & F: AAGGGTCAACCAGGGATACG & R: AAACACCCACAAGCCACAGG \\
\hline Gadd34 & F: GAGAAGACCAAGGGACGTGG & R:TCGATCTCGTGCAAACTGCT \\
\hline Hspa5 & F: GTGTGTGAGACCAGAACCGT & R:TAGGTGGTCCCCAAGTCGAT \\
\hline$R p / 22 / 1$ & F: ATGGCGCCGCAGAAAGACA & R: GACCACACGTAGCCAATCACG \\
\hline $\operatorname{Rps} 29$ & F: AGCCGACTCGTTCCTTTCTC & R:TTCAGCCCGTATTTGCGGAT \\
\hline Rp/13a & F: CGGCTGAAGCCTACCAGAAA & R: GGAGTCCGTTGGTCTTGAGG \\
\hline Cyclin B1 & F: AAGGCCAAGGTCAGTATGGC & R: CTCAGGCTCAGCAAGTTCCA \\
\hline Cyclin D1 & F: AGGCAGCGCGCGTCAGCAGCC & R:TCCATGGCGCGGCCGTCTGGG \\
\hline$c d k 2$ & F: CACAGGGCTTGCACGTCACT & R:TGTCTCCTGGCCTGCATCAC \\
\hline Ddit3 & F: GCAGCGACAGAGCCAGAATA & R: ATGTGCGTGTGACCTCTGTT \\
\hline$c d c 25 b$ & F: ATCCTTACCAGTGAGGCTGC & R: CTCTGGAAGCGCACATTCTC \\
\hline Mcm4 & F: CAAGGTTCAACCAGGGGACA & R: ATGCAGACGTTTTGCATCCG \\
\hline Mcm2 & F: AGAAGTTCAGCGTCATGCGGAGTA & R: CCCAAAGCGGTTGCGTTGATATGT \\
\hline$C d k 1$ & F: AAGTGTGGCCAGAAGTCGAG & R: AAAGTACGGGTGCTTCAGGG \\
\hline Gadd45a & F: CTGCAGAGCAGAAGACCGAA & R: GCAGGCACAGTACCACGTTA \\
\hline Bax & F: GCCTCCTCTCCTACTTC & R: CCTCAGCCCATCTTCTT \\
\hline $\mathrm{BCl}-2$ & F: CACTTGCCACTGTAGAGA & R: GCTTCACTGCCTCCTT \\
\hline
\end{tabular}




\section{Statistical analysis}

Statistical significance was calculated by one-way analysis of variance. All data were expressed as the mean \pm standard error of the mean (SEM). $p<0.05$ was considered statistically significant.

\section{Results}

\section{MPEE reduced the viability of $\mathrm{HCC}$ cells}

MPEE contained $42.5 \%$ of polysaccharides and $5.6 \%$ of flavonoids. The inhibitory effect of MPEE on the proliferation of HCC cells was determined by inverted microscope and MTT assay. After treatment with different concentrations $(0,25,50,75$ and $100 \mu \mathrm{g} / \mathrm{mL})$ of MPEE and cisplatin for 24 and 48 h, H22 cells showed small and round morphology, and cell numbers were enormously decreased (Fig. 1A). Compared to untreated cells, the viability of $\mathrm{H} 22$ cells was dose- and time-dependently decreased and the IC50 values were $53.5 \mu \mathrm{g} / \mathrm{mL}$ at $24 \mathrm{~h}$ and $30.8 \mu \mathrm{g} / \mathrm{mL}$ at $48 \mathrm{~h}$ (Fig. 1B, C). Moreover, the viability of BEL-7404 and HepG2 cells was also dose-dependently reduced by MPEE treatment and the IC50 values for BEL-7404 and HepG2 cells were $108.4 \mu \mathrm{g} / \mathrm{mL}$ and $118.4 \mu \mathrm{g} / \mathrm{mL}$ at $24 \mathrm{~h}$, respectively (Fig. 1D, E). Although MPEE reduced the viability of normal liver NCTC1469 cells, the IC50 value $(168.9 \mu \mathrm{g} / \mathrm{mL})$ is much higher than that of HCC cells (Fig. 1F). Moreover, the effect of MPEE on the viability of murine splenocytes was also detected. We found that MPEE had low cytotoxic effect on splenocytes (Fig. 1G). The results suggested that MPEE significantly reduced the viability of HCC cells with low cytotoxicity on normal cells.

\section{MPEE induced cell cycle arrest in $\mathrm{H} 22$ cells}

The nuclear morphology of $\mathrm{H} 22$ cells was further detected using Hoechst 33258 staining after treatment with MPEE for $24 \mathrm{~h}$. The nuclei of MPEE-treated cells showed chromatin condensation and fragmentation, while the nuclei of untreated cells showed homogeneous staining (Fig. 2A). To investigate whether MPEE induces cell cycle arrest in $\mathrm{H} 22$ cells, cells were treated with different concentrations $(0,25,50$ and $75 \mu \mathrm{g} / \mathrm{mL})$ of MPEE for $24 \mathrm{~h}$ and stained with PI. As shown in Fig. 2B, C, cell cycle was arrested at G0/G1 phase upon low concentration of MPEE treatment, while it was arrested at G2/M phase upon high concentrations of MPEE treatment. The proportions of sub-G1 cells were also significantly increased in a dose-dependent manner.

The expression of cell cycle-related genes was analyzed by transcriptome analysis and verified by qRT-PCR. After treatment with $75 \mu \mathrm{g} / \mathrm{mL}$ MPEE for $24 \mathrm{~h}$, total RNA was isolated to carry out transcriptome analysis. Most genes related to cell cycle were down-regulated except Gadd $45 \alpha$ and Sfn (Fig. 2D). qRT-PCR was used to verify the expression of Cdk2, Cyclin D1, Cdk1, Mcm2, Mcm4, Cyclin B1, Cdc25b and Gadd45 $\alpha$, which was consistent with transcriptome analysis (Fig. 2E). The protein levels of Cyclin B1, Cdk2 and Cyclin D1 were also significantly reduced by MPEE treatment in a dose-dependent manner (Fig. 2F; Additional file 1: Fig. S1). The results showed that MPEE induced cell cycle arrest through regulating the expression of cell cycle-related genes.

\section{MPEE induced apoptosis of HCC cells}

MPEE caused the chromatin condensation and fragmentation that was the characterization of apoptosis. Therefore, the apoptosis of HCC cells was analyzed by Annexin V-FITC and PI staining after treatment with different concentrations $(0,25,50$ and $75 \mu \mathrm{g} / \mathrm{mL})$ of MPEE for $24 \mathrm{~h}$. The results showed that the percentages of apoptosis $\mathrm{H} 22$ cells including early $\left(\mathrm{AnnexinV}^{+} \mathrm{PI}^{-}\right)$and late $\left(\right.$ Annexin $\mathrm{V}^{+} \mathrm{PI}^{+}$) apoptosis were significantly increased after MPEE treatment (Fig. 3A, B). The similar results were observed in BEL-7404 and HepG2 cells (Fig. 3D, F). Although MPEE also induced necrosis $\left(\mathrm{AnnexinV}^{-} \mathrm{PI}^{+}\right.$) in HCC cells (Fig. 3C, E, G), it mainly induced apoptosis. The results indicated that MPEE induced apoptosis of HCC cells.

\section{MPEE activated mitochondria-dependent apoptosis pathway}

Mitochondrial membrane potential $(\Delta \psi \mathrm{m})$ plays a critical role in the activation of intrinsic apoptosis pathway, which can be monitored by JC-1 staining. Red and green fluorescences represent JC-1 aggregate and monomer, respectively and the increase of green fluorescence indicates the reduction of $\Delta \psi \mathrm{m}$. H22 cells were treated with MPEE for $24 \mathrm{~h}$ and stained with JC-1 dye. We found that the green fluorescence in $\mathrm{H} 22$ cells was significantly enhanced by MPEE treatment (Fig. 4A, B), indicating that $\Delta \psi \mathrm{m}$ was lessened. $\Delta \psi \mathrm{m}$ is strictly regulated by proteins of the B cell lymphoma 2 (Bcl-2) family including anti-apoptotic Bcl-2 and pro-apoptotic Bcl-2-associated $\mathrm{X}$ protein (Bax). Therefore, the RNA and protein levels of $\mathrm{Bax}$ and $\mathrm{Bcl}-2$ were detected by qRT-PCR and Western blot after MPEE treatment for $24 \mathrm{~h}$. Consistently, the levels of Bax and Bcl-2 were increased and decreased at both mRNA and protein levels, respectively (Fig. 4C, D; Additional file 1: Fig. S1), which caused the reduction of $\Delta \psi \mathrm{m}$. Depletion of $\Delta \psi \mathrm{m}$ leads to the release of cytochrome $c$ into the cytoplasm to initiate apoptosis cascade [25]. After treatment with MPEE for $24 \mathrm{~h}$, total protein of $\mathrm{H} 22$ cells was isolated to test the levels of cytochrome $c$ by Western blot. Consistently, the levels of cytochrome $c$ were greatly increased upon MPEE treatment (Fig. 4C; Additional file 1: Fig. S1). We subsequently measured the activation of caspase cascade induced by 

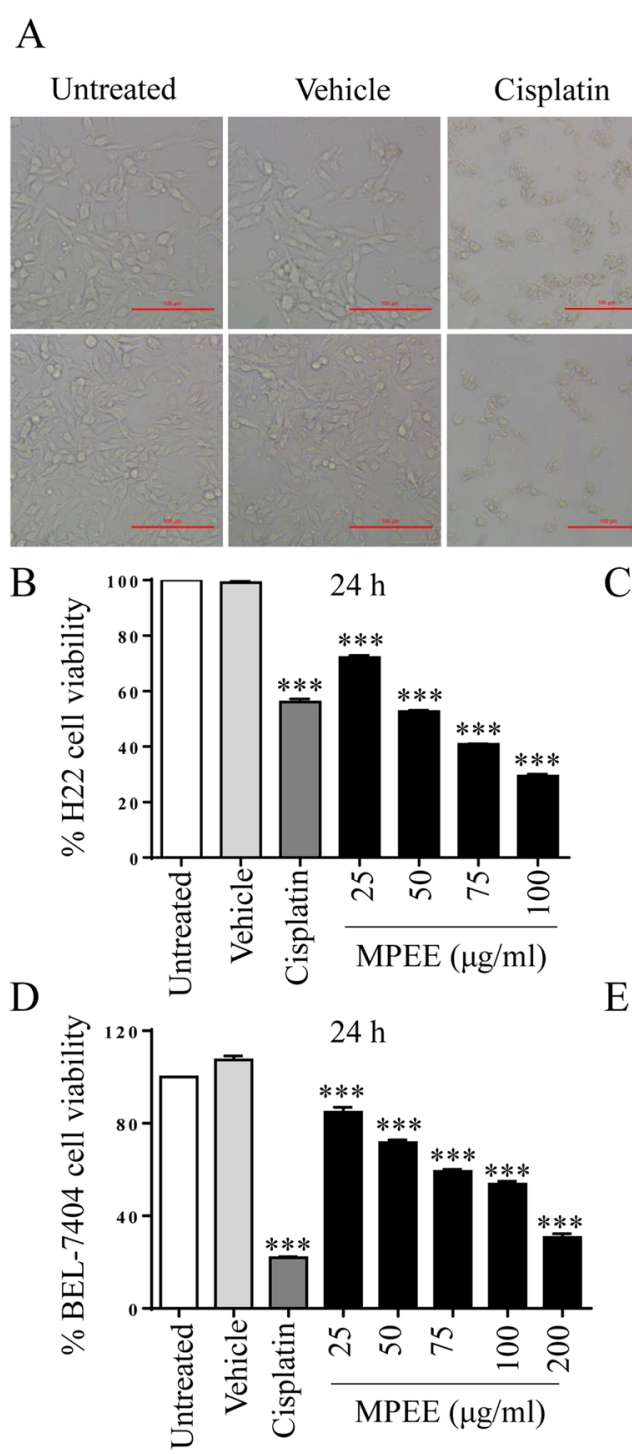

$\mathrm{E}$
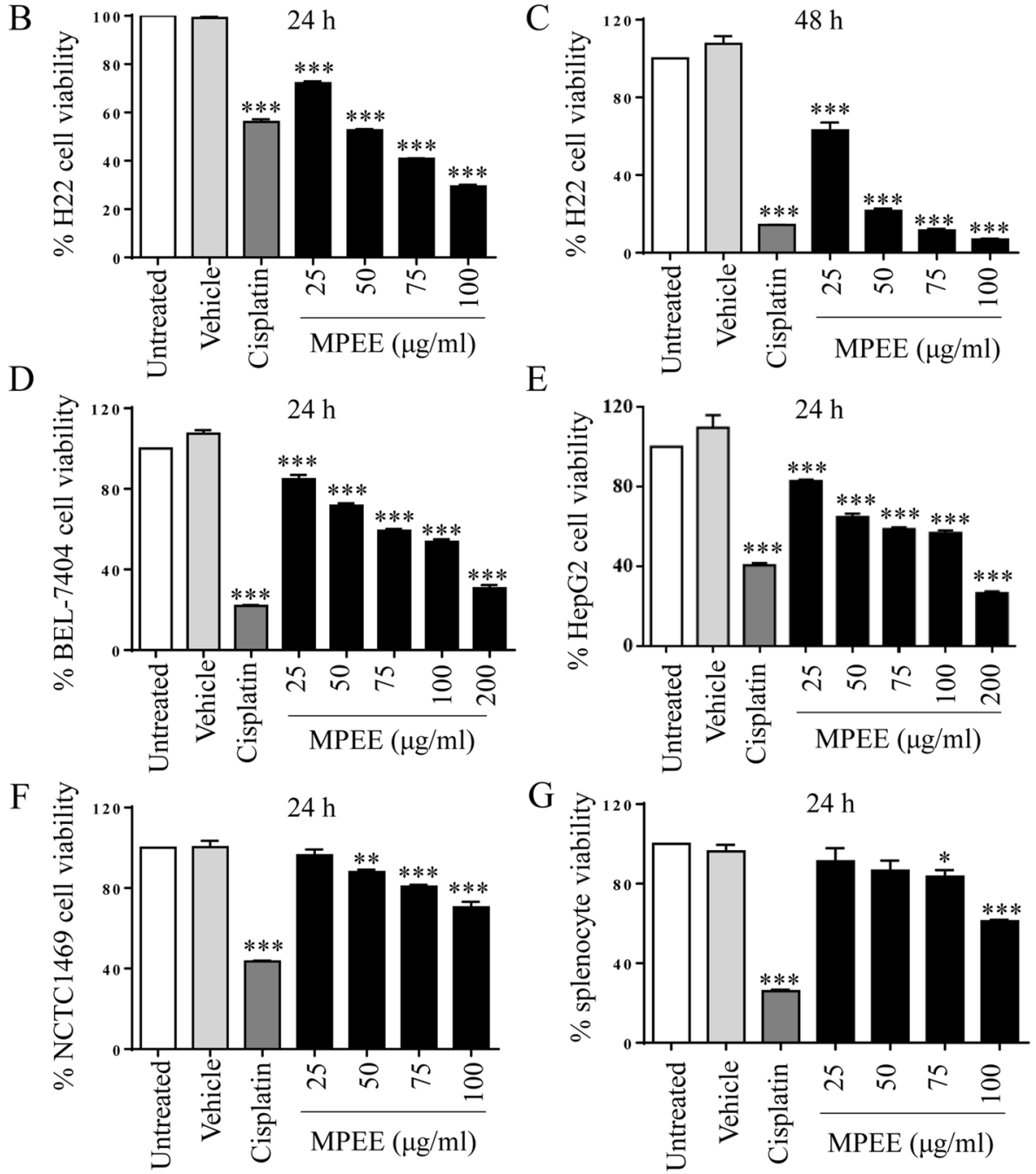

Fig. 1 Effects of MPEE on the proliferation of H22, BEL-7404, HepG2 and NCTC1469 cells and splenocytes. A After MPEE treatment for $24 \mathrm{~h}$ and $48 \mathrm{~h}$, the morphological changes of $\mathrm{H} 22$ cells were observed by inverted microscope. B-C The viability of $\mathrm{H} 22$ cells was measured by MTT assay after MPEE treatment for 24 and 48 h. D-F The viability of BEL-7404, HepG2 and NCTC1469 cells after MPEE treatment for 24 h. G The viability of splenocytes from C57BL/ 6 mice after MPEE treatment for $24 \mathrm{~h}$. Data were analyzed by ANOVA. ${ }^{*} p<0.05 ;{ }^{* *} p<0.01 ;{ }^{* * *} p<0.001$ compared to untreated group 

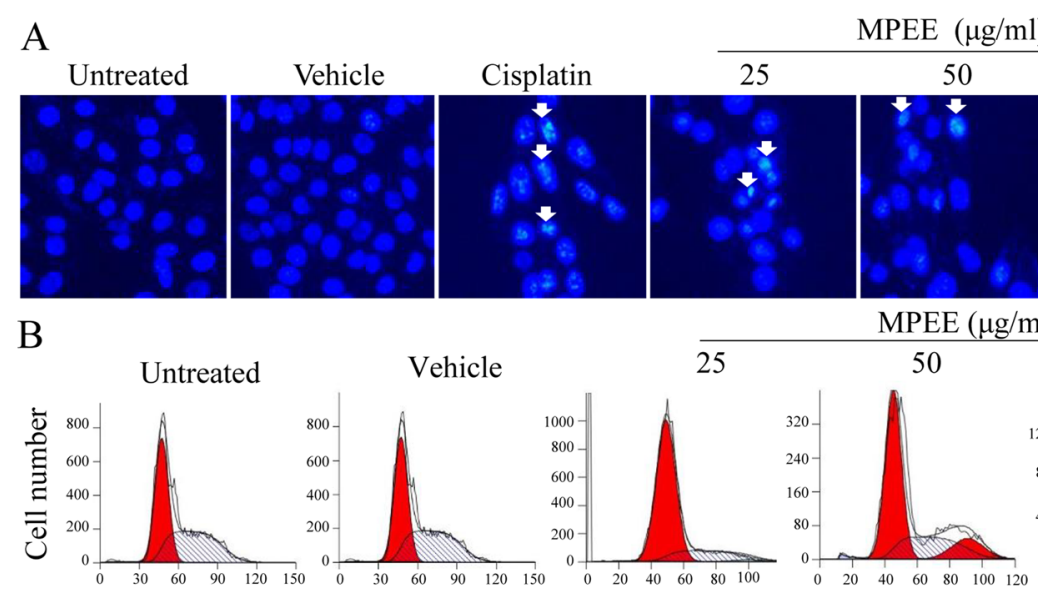

MPEE $(\mu \mathrm{g} / \mathrm{ml})$
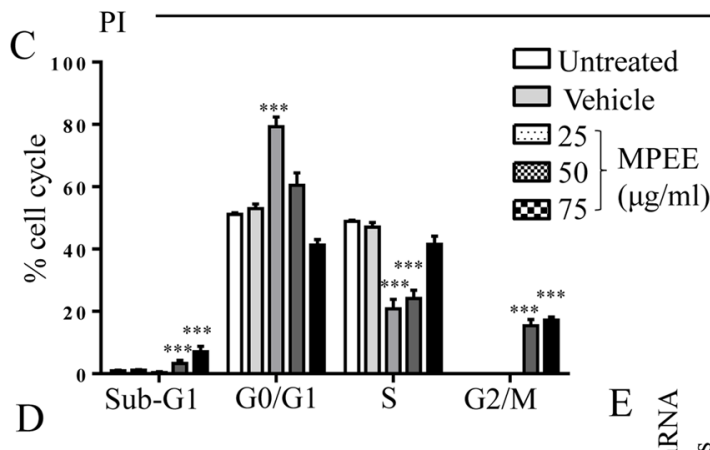

F Cyclin B1

\section{Cdk2}

Cyclin D1

$\beta$-actin

Untreated \begin{tabular}{llr}
$25 \quad 50 \quad 75$ \\
\cline { 2 - 2 }
\end{tabular}

D
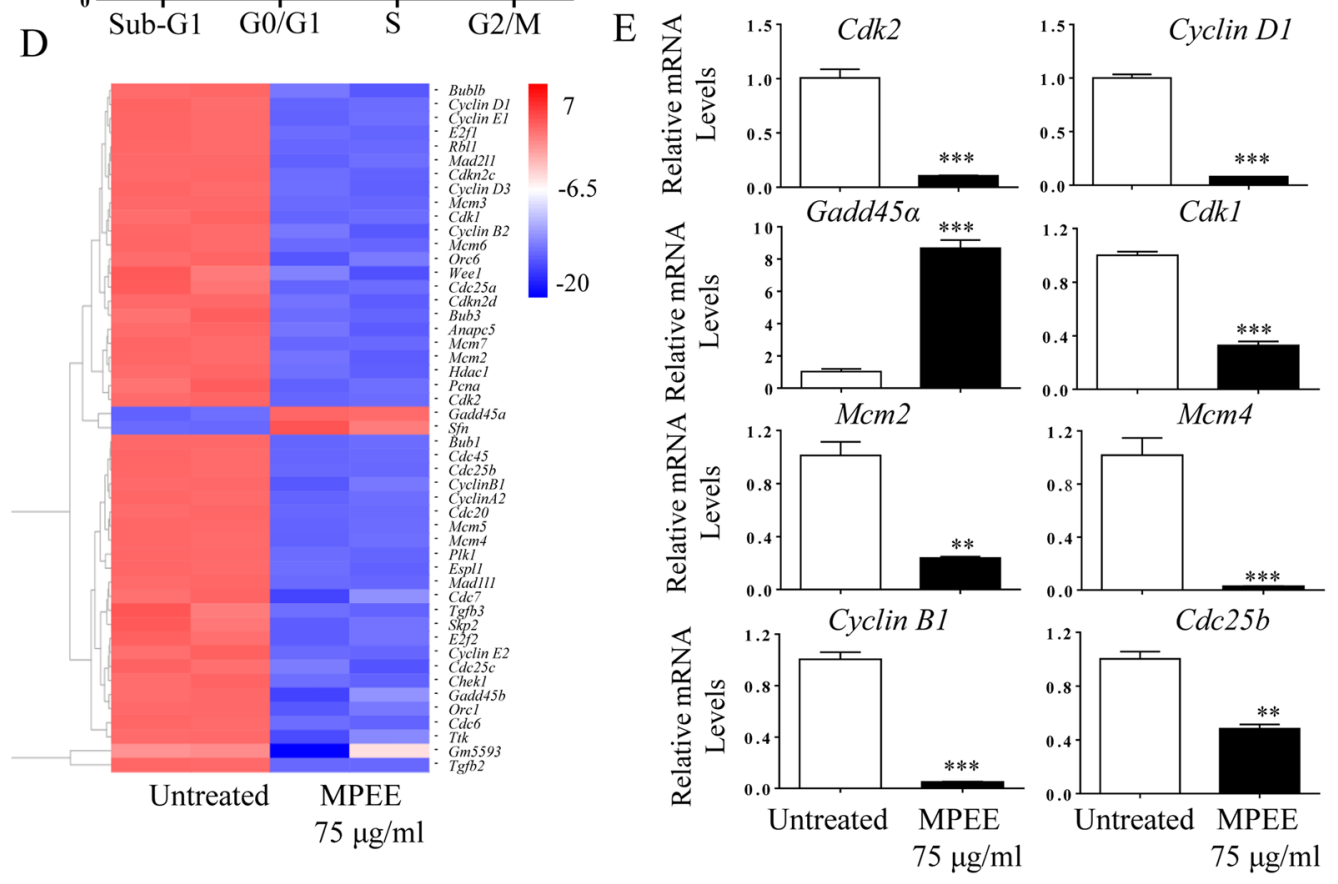

Fig. 2 Nuclear morphology and cell cycle distribution of $\mathrm{H} 22$ cells upon MPEE treatment. $\mathrm{H} 22$ cells were treated with different concentrations of MPEE for 24 h. A After staining with Hoechst 33258, nuclear morphology of H22 cells was observed by inverted fluorescence microscopy. The arrows indicated the chromosomal condensation. B-C Cell cycle phase distribution was analyzed by flow cytometry following PI staining. D Heatmap of clustered cell cycle associated genes as evaluated by transcriptome analysis. E The mRNA levels of Cdk2, Cyclin D1, Gadd45a, Cdk1, Mcm2, Mcm4, Cyclin B1 and Cdc25b were analyzed by qRT-PCR. F The protein levels of Cyclin B1, Cyclin D1 and Cdk2 were detected by Western blot. Data were analyzed by ANOVA. ${ }^{* *} p<0.01 ;{ }^{* *} p<0.001$ compared to untreated group 

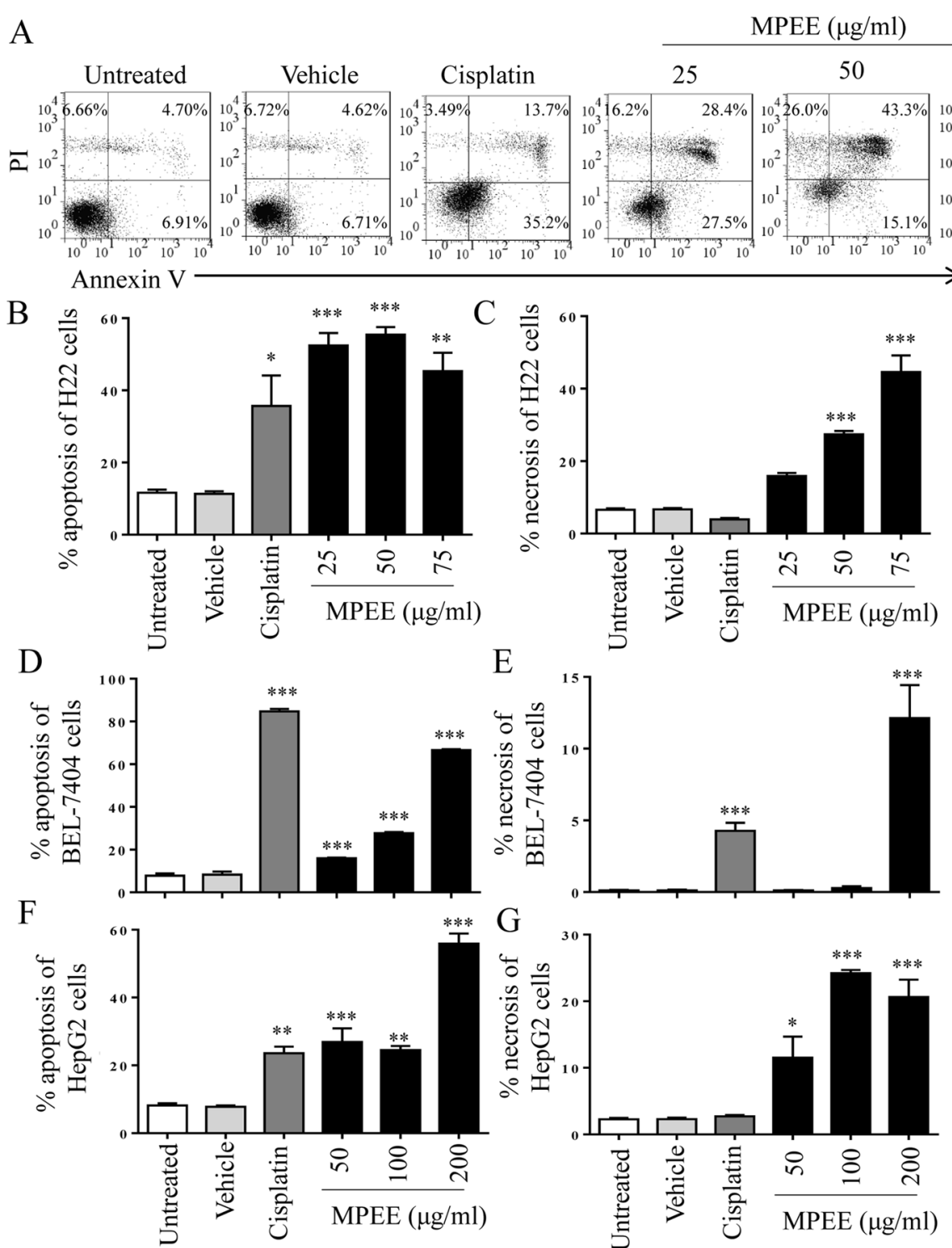

Fig. 3 The apoptosis of H22, BEL-7404 and HepG2 cells induced by MPEE treatment. Different concentrations of MPEE were used to treat H22, BEL-7404 and HepG2 cells for $24 \mathrm{~h}$. A-C The apoptosis and necrosis of H22 cells were analyzed by flow cytometry following Annexin V/PI staining. D-G The apoptosis and necrosis of BEL-7404 and HepG2 cells were shown. Data were analyzed by ANOVA. ${ }^{*} p<0.05 ;{ }^{* *} p<0.01{ }^{* * *} p<0.001$ compared to untreated group

mitochondria-dependent pathway and found that the levels of cleaved caspase- 9 and -3 were greatly increased by MPEE treatment compared with the untreated control. At the same time, MPEE promoted the cleavage of caspase-8 (Fig. 4E; Additional file 1: Fig. S1). Sequentially, the upregulated level of cleaved DNA repair enzyme of poly (ADP-ribose) polymerase (PARP) was observed. The results suggested that caspase cascade was involved in the apoptosis induced by MPEE.

To investigate the role of caspase in the induction of apoptosis, H22 cells were pretreated with Z-VAD-FMK
(FMK, a broad-spectrum caspase inhibitor) and AcDEVD-CHO (CHO, a caspase 3 inhibitor), and then treated with MPEE. After $24 \mathrm{~h}$, the apoptosis of H22 cells was analyzed by flow cytometry. The pretreatment of FMK and $\mathrm{CHO}$ significantly decreased the apoptosis of $\mathrm{H} 22$ cells induced by MPEE (Fig. 5A-F), suggesting that mitochondria-dependent pathway partially mediated MPEE-induced apoptosis. 

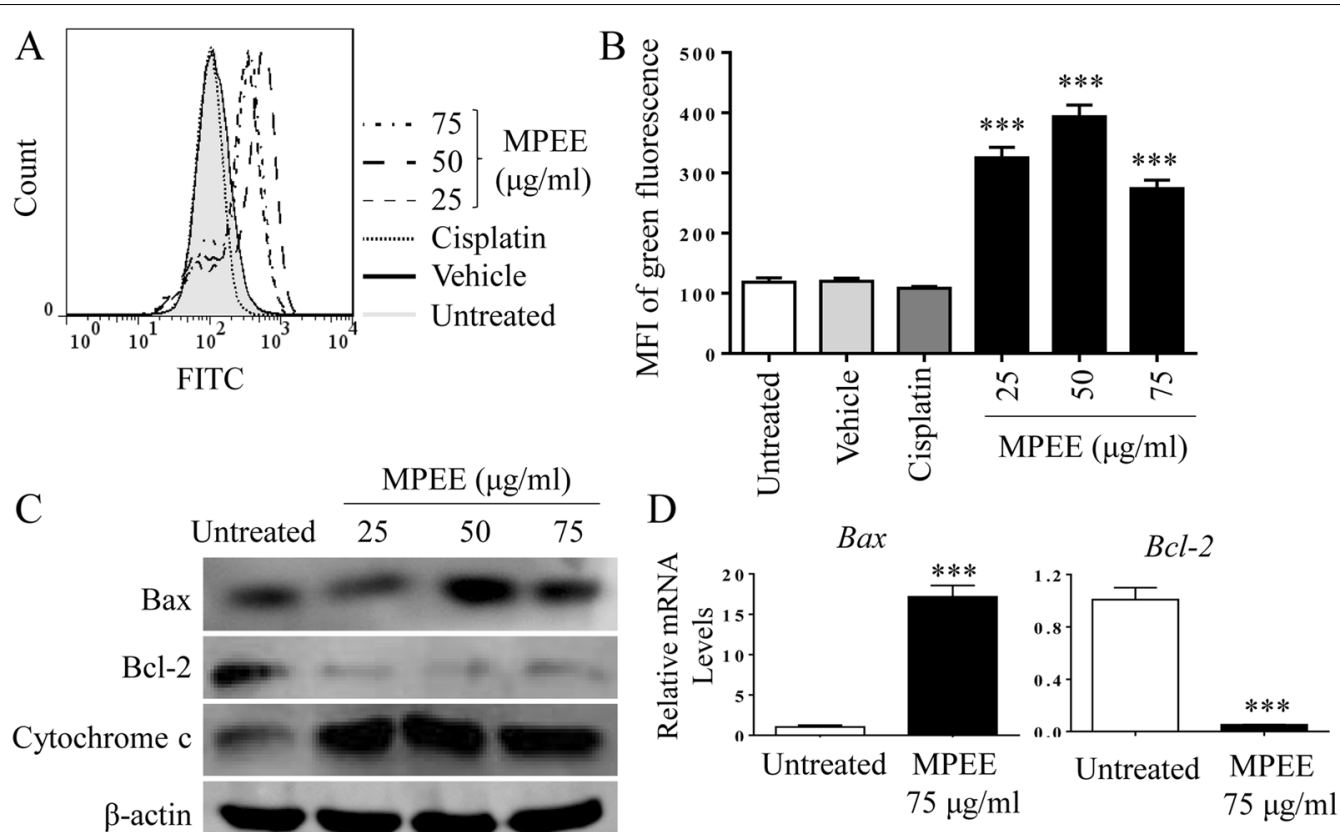

E $\quad$ Untreated \begin{tabular}{lll} 
MPEE $(\mu \mathrm{g} / \mathrm{ml})$ \\
\cline { 3 - 4 }
\end{tabular}

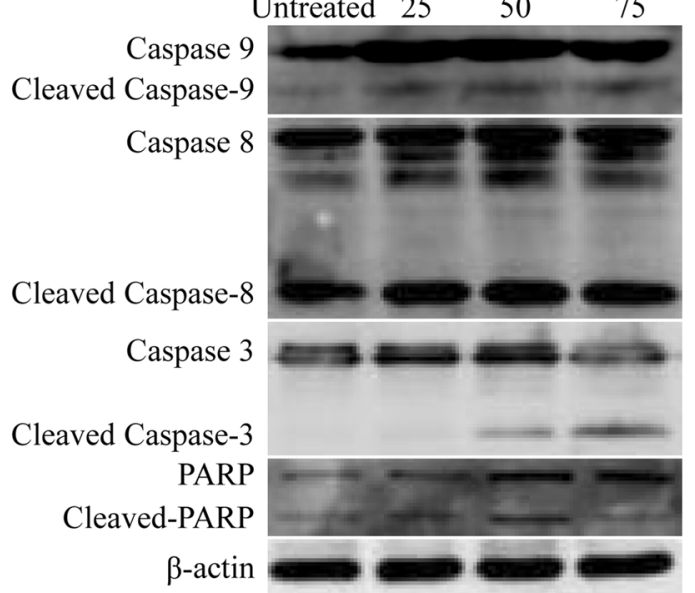

Fig. 4 The effects of MPEE on $\Delta \psi_{m}$ and caspase cascade in $\mathrm{H} 22$ cells. $\mathrm{H} 22$ cells were treated with different concentrations of MPEE for $24 \mathrm{~h}$. A, B Cells were stained with JC-1 and the fluorescence changes were analyzed by flow cytometry. CThe protein levels of Bax, Bcl-2 and cytochrome $C$ were detected by Western blot. D The mRNA levels of $B a x$ and $B C l-2$ were analyzed by qRT-PCR. E The levels of cleaved-caspases and -PARP were detected by Western blot. Data were analyzed by ANOVA. ${ }^{* * *} p<0.001$ compared to untreated group

\section{MPEE induced reactive oxygen species (ROS) production and endoplasmic reticulum (ER) stress}

It has been reported that ROS production was involved in the induction of mitochondrial dysfunction and ER stress [26]. We found that MPEE significantly induced ROS production using both flow cytometry and inverted fluorescence microscopy after treatment for $24 \mathrm{~h}$ (Fig. 6AC). Consistently, the transcriptome analysis showed that MPEE significantly up-regulated 70 genes related to protein processing in ER and 53 genes related to Ribosome
(Fig. 7A), suggesting that ER stress signaling pathway was activated. The expression of Rpl22l1, Rpl13a, Rps29, Srp14, Srprb, Srp19, Srp72, Srp68, Srpr, Gadd34, Wfs1, Ddit3, Atf6 and Hspa5 was verified by qRT-PCR, which was consistent with transcriptome analysis (Fig. 7B).

We further investigated whether the ER stress pathway was involved in apoptosis induced by MPEE in H22 cells. After treatment with different concentrations of MPEE for $24 \mathrm{~h}$, the level of phosphorylated protein kinase-like ER kinase (p-PERK) was significantly increased (Fig. 7C; 
A

A $\quad$ MPEE $(\mu \mathrm{g} / \mathrm{ml})$

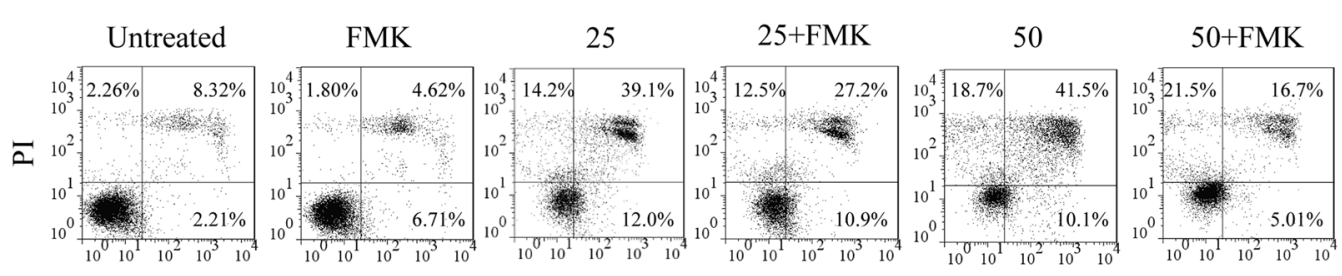

B

$$
\text { Annexin V - }
$$

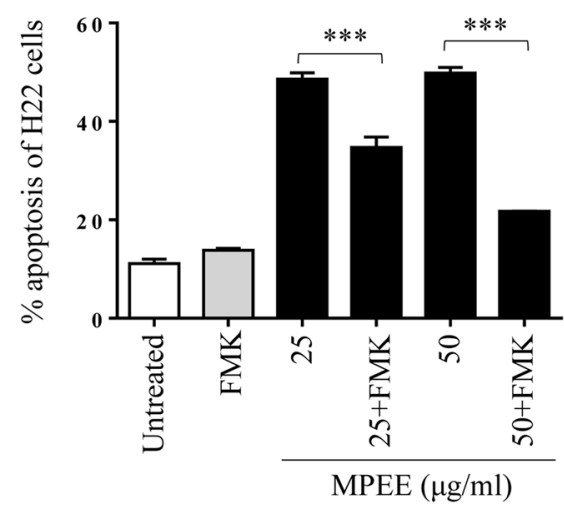

C

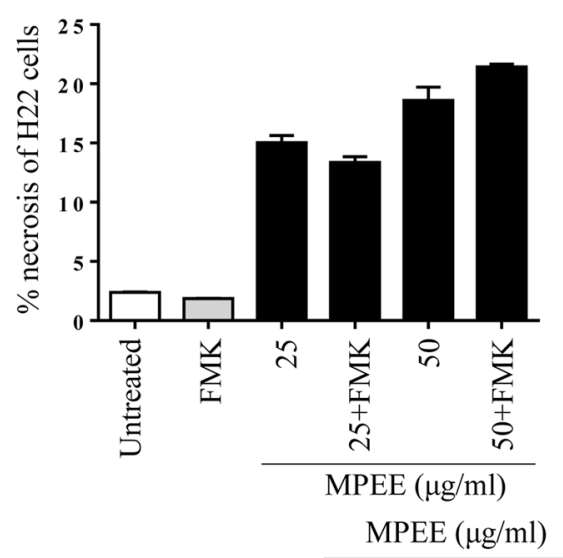

D

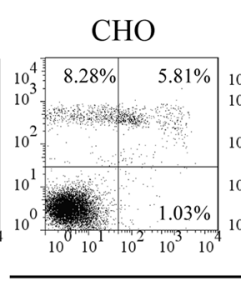

Cisplatin
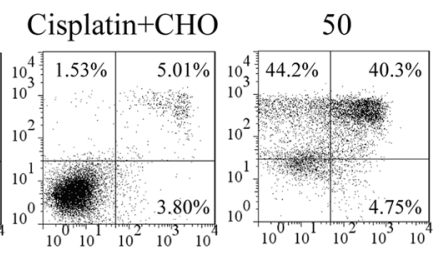

$50+\mathrm{CHO}$

$\bar{a}$

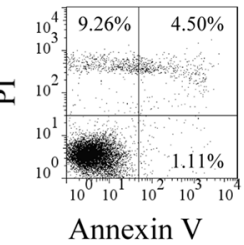

$\mathrm{E}$

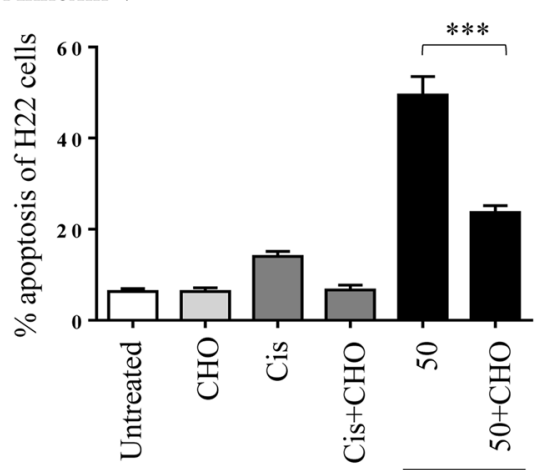

MPEE $(\mu \mathrm{g} / \mathrm{ml})$

F

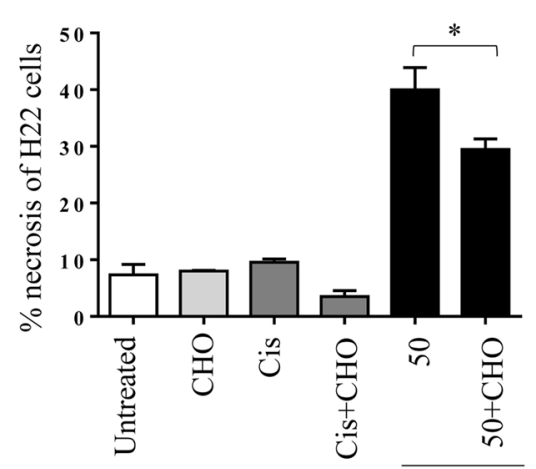

$\operatorname{MPEE}(\mu \mathrm{g} / \mathrm{ml})$

Fig. 5 The effect of caspase inhibitors on apoptosis of H22 cells induced by MPEE. H22 cells were pretreated with $15 \mu \mathrm{M}$ FMK or $20 \mu \mathrm{M}$ CHO for $2 \mathrm{~h}$, and then treated with MPEE. After $24 \mathrm{~h}$, apoptosis and necrosis of $\mathrm{H} 22$ cells were analyzed by flow cytometry. FMK pretreatment was shown in $\mathbf{A}-\mathbf{C}$ and $\mathrm{CHO}$ pretreatment was shown in $\mathbf{D}-\mathbf{F}$. Data were analyzed by ANOVA. ${ }^{*} p<0.05 ;{ }^{* * *} p<0.001$ compared to untreated group

Additional file 2: Fig. S2). PERK releases glucose-regulated protein 78 (GRP78/BiP) and phosphorylates eukaryotic translation initiation factor 2 alpha (eIF2 $\alpha$ ), which lead to a general decrease in protein translation [27]. We found that the phosphorylation of eIF $2 \alpha$ and the level of
GPR78 were up-regulated by MPEE treatment. In addition, activating transcription factor 6 (ATF6), an ER type II transmembrane protein, was also up-regulated. ATF6 entered the nucleus to activate the expression of GRP78 and $\mathrm{C} / \mathrm{EBP}$ homologous protein (CHOP) genes. We also 

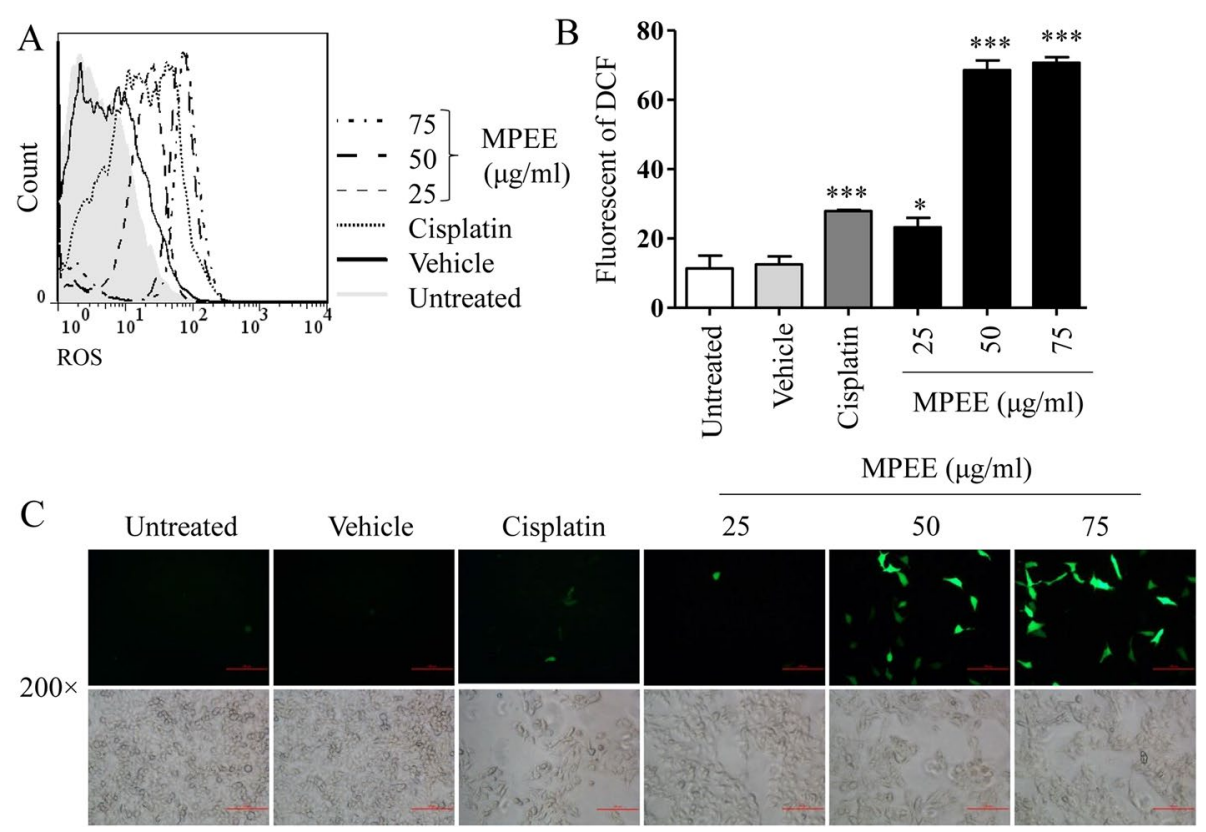

Fig. 6 ROS production in $\mathrm{H} 22$ cells induced by MPEE. $\mathrm{H} 22$ cells were treated with different concentrations of MPEE for $24 \mathrm{~h}$ and stained with DCFH-DA. A, B Samples were analyzed by flow cytometry. C Samples were observed using inverted fluorescence microscopy. Data were analyzed by ANOVA. ${ }^{*} p<0.05 ;{ }^{* *} p<0.001$ compared to untreated group

found that MPEE significantly increased the levels of CHOP (Fig. 7C; Additional file 2: Fig. S2). The results indicated that MPEE might induce apoptosis in H22 cells through ER stress signaling pathway.

\section{MPEE suppressed in vitro migration and in vivo growth of $\mathrm{H} 22$ cells}

Wound healing method was used to determine the migration of $\mathrm{H} 22$ cells in vitro. We found that MPEE significantly suppressed $\mathrm{H} 22$ cell migration in a dosedependent manner (Fig. 8A-C). H22 tumor mouse model was further used to evaluate the antitumor effect of MPEE. After 6 days of H22 cell injection, tumor mice were intraperitoneally treated with DMSO, cisplatin and MPEE. The body weight of mice and tumor sizes were monitored at indicated time points. Compared with untreated and DMSO groups, cisplatin significantly reduced the body weight but MPEE did not significantly change the body weight, suggesting that the selected doses of MPEE had no obvious side effect (Fig. 9A). Interestingly, the tumor growth in mice treated with both 50 and $100 \mathrm{mg} / \mathrm{kg}$ of MPEE was significantly inhibited (Fig. 9B). Moreover, both doses of MPEE greatly improved the survival of tumor mice $(50 \mathrm{mg} / \mathrm{kg}$ : 6 out of 8; $100 \mathrm{mg} / \mathrm{kg}: 7$ out of 8) compared with model groups ( 0 out of 8$)$ at the end of the experiment (Fig. 9C). The results showed that MPEE suppressed $\mathrm{H} 22$ cell growth in vivo and improved the survival of tumor mice.
Qualitative and quantitative analysis of the active ingredients in MPEE

The MPEE was characterized by LC-Q-TOF-MS and compounds were identified according to mass spectrometry data under both negative and positive ESI mode (Additional file 3: Fig. S3). 67 ingredients with the relative content more than $100 \mathrm{ng}$ were found under negative ESI mode, which included nine fatty Acyls, eight flavonoids and four benzopyrans [28-48] (Additional file 4: Table S1). The most abundant component is 3,5,7-trihydroxy-2-(3-hydroxyphenyl)-4H-chromen4-one, which belongs to flavonoids with molecular weight of 286.04 and retention time of $6.74 \mathrm{~min}$. Meanwhile, compound identification was performed according to mass spectrometry data under positive ESI mode (Additional file 3: Fig. S3), 20 ingredients with the relative content more than $50 \mathrm{ng}$ were identified under positive ESI mode (Additional file 5: Table S2), which included two flavonoids, one isoflavonoids, two prenol lipids, one kind of steroids and steroid derivatives, coumarins and derivatives and stilbenes [49-54]. The most abundant component is beta-patchoulene, which belongs to polycyclic hydrocarbons with molecular weight of 204.19 and retention time of $12.06 \mathrm{~min}$. 

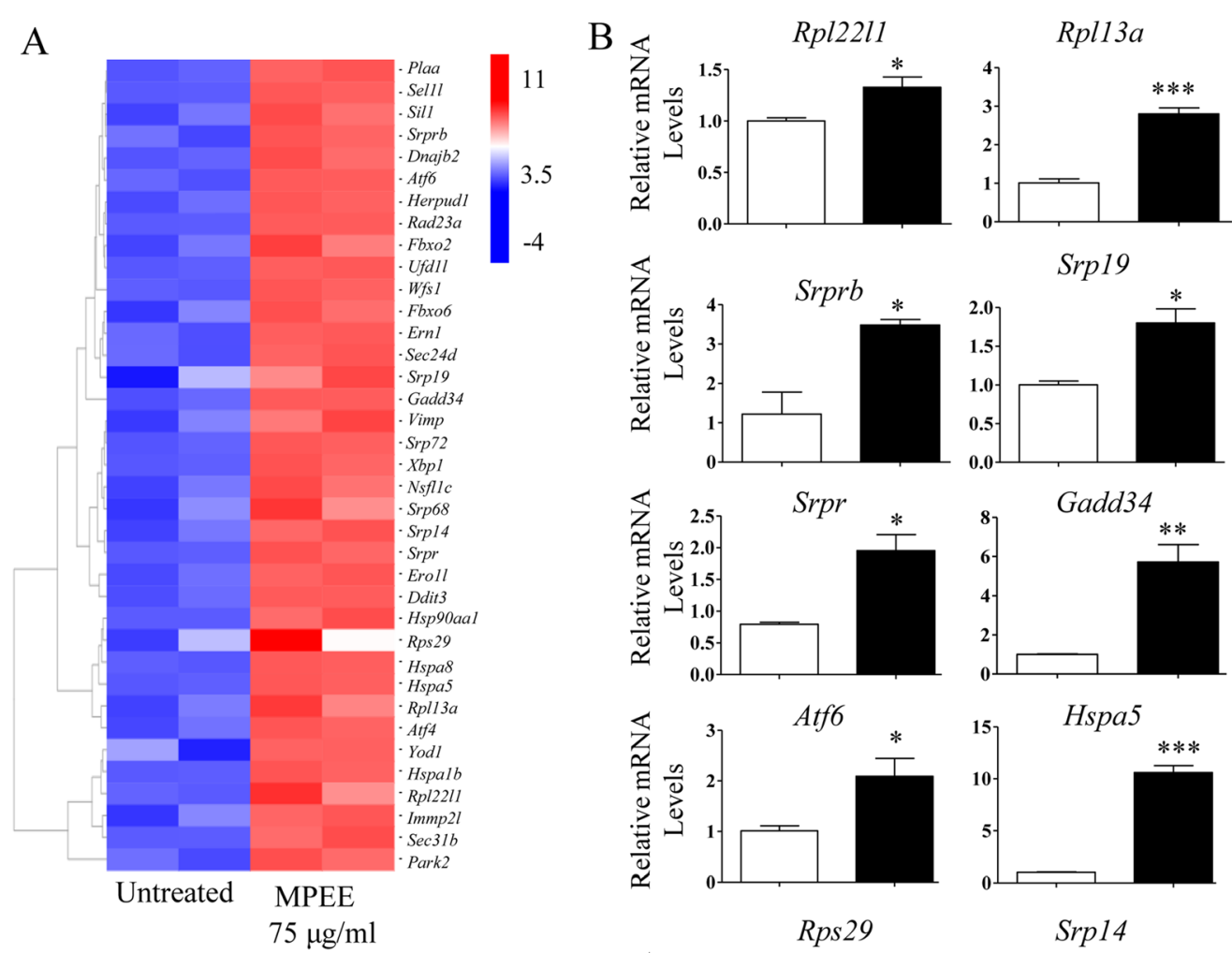

$\operatorname{Srp19}$
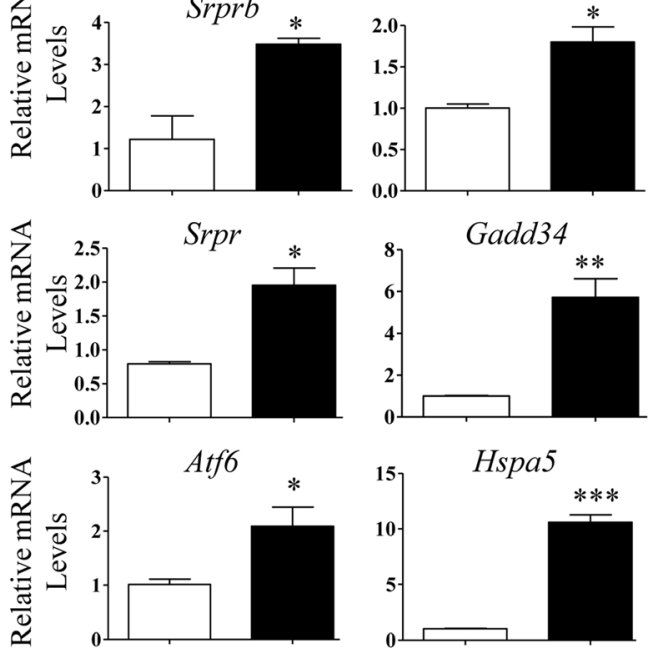

C

Rps29
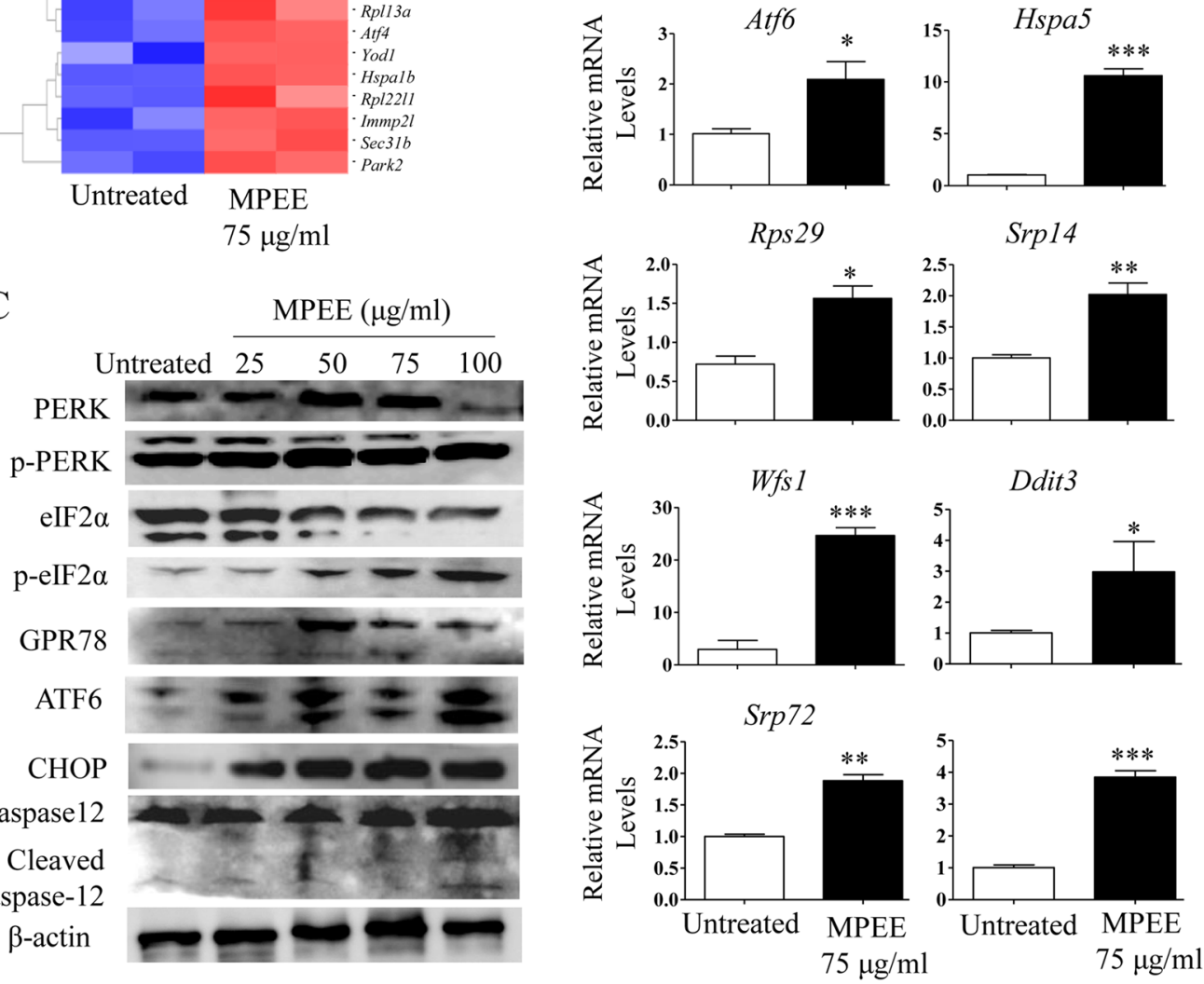

Fig. 7 MPEE activated ER stress in $\mathrm{H} 22$ cells. $\mathrm{H} 22$ cells were treated with MPEE for $24 \mathrm{~h}$ and the total RNA was isolated. A Heatmap of clustered ER stress-associated genes as evaluated by transcriptome analysis. B The mRNA levels for Rpl2211, Rp/13a, Srprb, Srp19, Srpr, Gadd34, Atf6, Hspa5, Rps29, Srp14, Wfs 1, Ddit3, Srp72 and Srp68 were analyzed by qRT-PCR. C The levels of ER stress-associated proteins were analyzed by Western blot. Data were analyzed by ANOVA. ${ }^{*} p<0.05 ;{ }^{* *} p<0.01 ;{ }^{* *} p<0.001$ compared to untreated group

\section{Discussion}

Compared with conventional chemotherapeutics, natural compounds can exert potent antitumor effect with or without minor adverse effects [55]. A number of plant-derived natural products have been investigated for their antitumor activities [21, 23, 56]. Recently, it has been reported that bryophytes can induce apoptosis and cell cycle arrests $[19,57]$. In this study, our results showed 


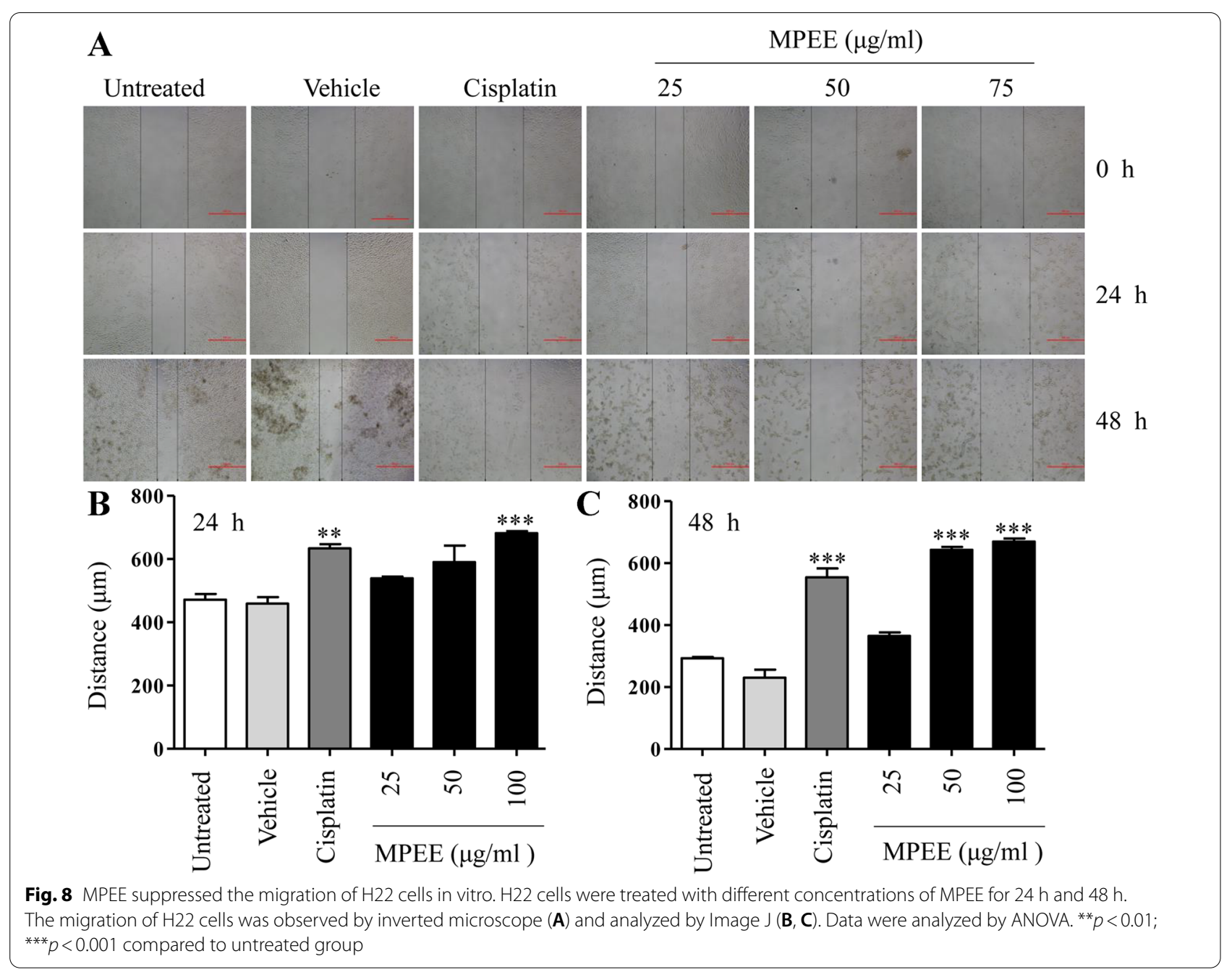

that MPEE inhibited HCC cell growth both in vitro and in vivo, which might induce cell cycle arrest and apoptosis of HCC cells through intrinsic- and ER stress-associated signaling pathways.

The antiproliferative activity of MPEE was first examined. The results showed that MPEE significantly inhibited the growth of H22, HepG2 and BEL-7404 cells. Cellular proliferation is primarily controlled by the cell cycle, which consists of four sequential phases (G0/G1, S, G2, and M) [58]. Cyclin-dependent kinases (CDKs) and the cyclins are the key regulators of cell cycle transition $[59,60]$. Cdk2 regulates the cell cycle transition from $\mathrm{G} 1$ to $S$ phase [61]. Cyclin D1 is another regulator that drives G1 to $S$ phase progression and its dysregulation can be frequently found in human cancers including HCC [62]. Cyclin B is mainly involved in the completion of $\mathrm{M}$ phase [63]. In our study, we observed that low concentrations of MPEE treatment significantly induced $\mathrm{H} 22$ cell cycle arrest at G0/G1phase, and decreased the expression of
Cdk2 and cyclin D1 at both levels of mRNA and protein. However, high concentrations of MPEE arrested $\mathrm{H} 22$ cells at G2/M phase with a significant decrease of cyclin B expression, which might be due to the different components of MPEE to induce the cell cycle arrest at the different phases. Consistently, MPEE significantly downregulated the expression of Cdk1, which plays an important role in the transition from $G 2$ to $M$ phase [64]. It has been reported that $\mathrm{Cdc} 25 \mathrm{~b}$ activates $\mathrm{Cdk} 1 /$ cyclin $B$ but growth arrest and DNA damage-inducible 45 alpha (Gadd45a) inhibits the activation of Cdk1and Cdk1cyclinB complex [65]. We also found that MPEE downregulated and upregulated the expression of $\mathrm{Cdc} 25 \mathrm{~b}$ and Gadd45a, respectively. The results indicated that MPEE suppressed the growth of $\mathrm{HCC}$ cells by the induction of cell cycle arrest.

Minichromosome Maintenance (MCM) family is essential for DNA replication in each cell cycle. Mcm4 affects the DNA helicase activity of the Mcm2-7 


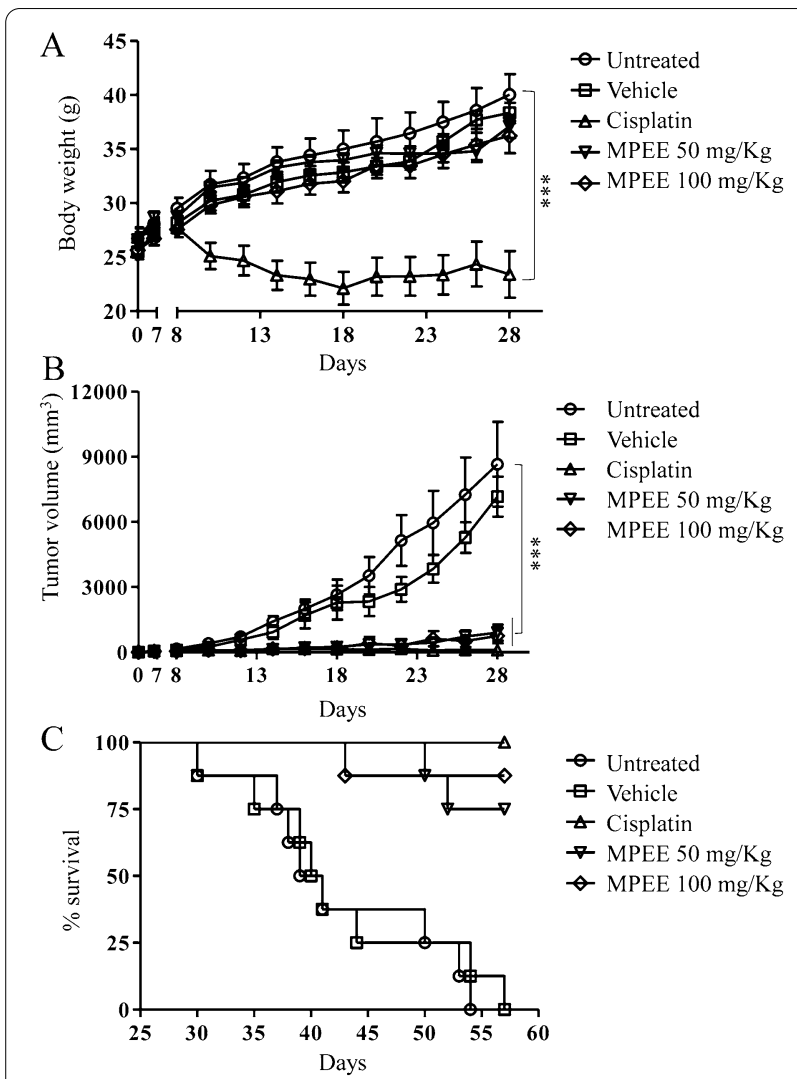

Fig. 9 MPEE inhibited $\mathrm{H} 22$ tumor growth in vivo. Tumor mouse model was established by injection of $\mathrm{H} 22$ cells. After 6 days, tumor mice (8 mice/group) were intraperitoneally treated with DMSO, cisplatin and MPEE. Body weight and tumor volumes were shown in $\mathbf{A}$ and $\mathbf{B}$, respectively. $\mathbf{C}$ The survival rate of tumor mice was monitored. Data were analyzed by ANOVA. ${ }^{* *} p<0.001$ compared to model group

complex. Mcm2 is associated with the progression from cirrhosis to HCC and poor cellular differentiation. MCMs were significantly up-regulated in HCC [66]. We observed that MPEE significantly reduced the expression of Mcm2 and Mcm4, suggesting that MPEE might suppress the growth of HCC cells through interference of DNA replication. It has been reported that cyclin D1 not only regulates the transition from $\mathrm{G} 1$ to $\mathrm{S}$ phase but also promotes tumor invasion and metastasis, and cyclin D1 deletion can reduce the migration of tumor cells [67]. Similarly, MPEE inhibited H22 cell migration in vitro, suggesting that MPEE might inhibit tumor invasion and metastasis.

Apoptosis also plays a crucial role for controlling the proliferation of cancer cells and has been considered as a major route to eradicate cancer cells [68]. Both caspase-independent and -dependent pathways can account for the programmed cell death $[69,70]$. Caspasedependent apoptosis can be induced by the intrinsic (mitochondria-dependent) pathway and the extrinsic (death receptor) pathway [71]. The loss of $\Delta \psi \mathrm{m}$ is the major characteristic of mitochondria-dependent apoptosis because it promotes the release of cytochrome $c$ from mitochondria to cytosol and activation of caspase-9. We found that MPEE reduced $\triangle \psi \mathrm{m}$ of $\mathrm{HCC}$ cells and increased the release of cytochrome $c$, which activated caspase-9. At the same time, MPEE also activated caspase-8. Therefore, both active caspase- 9 and -8 might activate caspase- 3 to degrade PARP. We further observed that both broad-spectrum caspase inhibitor and caspase 3 inhibitor significantly reduced apoptosis induced by MPEE. The results indicated that MPEE induced apoptosis in HCC cells through both intrinsic signaling pathways.

ER is well known to regulate cellular responses to stress. Aberrant accumulation of misfolded/unfolded proteins, oxidative stress and $\mathrm{Ca}^{2+}$ imbalance can activate ER stress [72, 73], which is involved in the induction of apoptosis [74]. ER stress-associated apoptosis in cancer cells represents the potential target for the development of cancer therapeutic drugs. We found that MPEE dramatically increased the ROS production in HCC cells, which might contribute to the activation of ER stress. The transcriptome analysis showed that a large number of upregulated genes including Atf6, Gadd34, Rps29, Srp14, Srp19, Srp72, and Srp68 were enriched in ribosome, protein export and ER stress-related signaling pathways [75]. These data suggested that MPEE induced ER stress in HCC cells. ER stress can activate the unfolded protein response (UPR), which includes PERK, ATF6 and inositol-requiring enzyme 1 (IRE1) signaling pathways [76]. Western blot result showed that the phosphorylation of PERK was up-regulated by MPEE treatment, which could release GRP78, phosphorylate eIF2 $\alpha$ and increase CHOP to induce apoptosis [77]. Consistently, the phosphorylation of eIF $2 \alpha$ and the levels of GPR7 8 and CHOP were up-regulated by MPEE treatment. Moreover, the RNA and protein levels of ATF6 were increased by MPEE treatment, which could enhance the expression of GPR78 and CHOP. CHOP could promote the expression of GADD34 and the up-regulated expression of GADD34 was observed upon MPEE treatment, which was involved in apoptosis [78]. The results indicated that MPEE induced apoptosis of HCC cells through ER stress signaling pathway. The various components of MPEE might be endowed the pleiotropic effects on the induction of cell cycle arrest and apoptosis through different signaling pathways.

Cisplatin is a well-known chemotherapeutic drug. It has been employed for treatment of numerous human cancers, such as testicular, ovarian, colorectal, bladder, lung and liver cancer. Cisplatin exerts anticancer effects 
via multiple mechanisms including its most prominent ability to cross-link with DNA to block transcription and replication, and induce mitochondria-dependent apoptosis. However, cisplatin can cause severe side effects, such as nephrotoxicity, cardiotoxicity and gastrointestinal toxicity $[79,80]$. In our study, MPEE significantly suppressed the growth of tumor and greatly improved the survival of tumor mice without obvious side effect. In the future study, we will investigate the antitumor effect of MPEE on the metastatic tumor mouse model.

\section{Conclusion}

MPEE suppressed the growth of HCC cells both in vitro and in vivo through induction of intrinsic- and ER stressassociated apoptosis. MPEE also inhibited the migration of HCC cells in vitro and improved the survival of tumor mice. These results indicate that MPEE may be a promising candidate for the treatment of HCC.

\begin{abstract}
Abbreviations
MPEE: Marchantia polymorpha ethanol extract; HCC: Hepatocellular carcinoma; ER: Endoplasmic reticulum; MTT: 3-(4,5-Dimethyl-2-thiazolyl)-2,5-diphenyl-2-H-tetrazolium bromide; DMSO: Dimethyl sulfoxide; PI: Propidium iodide; $\triangle \Psi$ M: Mitochondrial membrane potential; ROS: Reactive oxygen species; qRT-PCR: Quantitative real time polymerase chain reaction; PARP: Poly (ADP-ribose) polymerase; MCM: Minichromosome maintenance family; CDKs: Cyclin-dependent kinases; DCFH-DA: Dichlorodihydrofluorescein diacetate; BCL-2: The B cell lymphoma 2 family; Bax: Bcl-2-associated X protein; p-PERK: Phosphorylated protein kinase-like ER kinase; GRP78/BiP: PERK releases glucose-regulated protein 78; elF2a: Phosphorylates eukaryotic translation initiation factor 2 alpha; ATF6: Activating transcription factor 6; CHOP: C/EBP homologous protein; Gadd45a: DNA damage-inducible 45 alpha; UPR: The unfolded protein response; IRE1: Inositol-requiring enzyme 1.
\end{abstract}

\section{Supplementary Information}

The online version contains supplementary material available at https://doi. org/10.1186/s13020-021-00504-4.

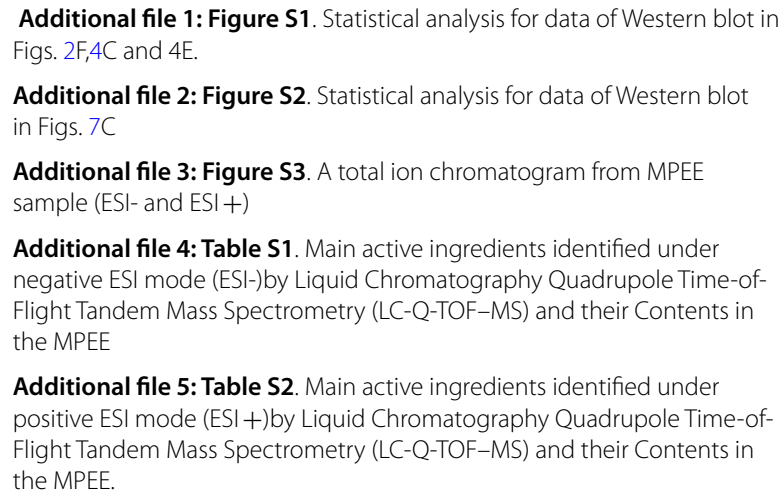

Additional file 2: Figure S2. Statistical analysis for data of Western blot in Figs. 7C

Additional file 3: Figure S3. A total ion chromatogram from MPEE sample (ESI- and ESI +)

Additional file 4: Table S1. Main active ingredients identified under negative ESI mode (ESI-)by Liquid Chromatography Quadrupole Time-ofFlight Tandem Mass Spectrometry (LC-Q-TOF-MS) and their Contents in the MPEE

Additional file 5: Table S2. Main active ingredients identified under positive ESI mode (ESI +)by Liquid Chromatography Quadrupole Time-ofFlight Tandem Mass Spectrometry (LC-Q-TOF-MS) and their Contents in the MPEE.

\section{Acknowledgements}

Not applicable.

\section{Authors' contributions}

FZ, AA, XH and PY performed the experiments; FZ, AA, WW, LX and JL analyzed the data; MS indentified and collected Marchantia polymorpha L. FZ, WW and
$J$ designed the experiments and wrote the manuscript. All authors read and approved the final manuscript.

\section{Funding}

This work was supported by the National Natural Science Foundation of China (U1803381 to Jinyao Li and 31860258 to Lijie Xia), the Doctoral Start-up Foundation of Xinjiang University (2017 to Jinyao Li and BS150240 to Weilan Wang) and the "Tianshan Youth Project"Young Ph.D. Science and Technology Talents Project (2017Q077) to Lijie Xia.

\section{Availability of data and materials}

All the data used to support the findings of this study are available from the corresponding author upon reasonable request.

\section{Declarations}

\section{Ethics approval and consent to participate}

The experimental protocol was approved by the Committee on the Ethics of Animal Experiments of Xinjiang Key Laboratory of Biological Resources and Genetic Engineering (BRGE-AE001).

\section{Consent for publication}

This manuscript is approved by all authors for publication.

\section{Competing interests}

The authors declare that they have no competing interests.

Received: 11 July 2021 Accepted: 12 September 2021

Published online: 28 September 2021

\section{References}

1. Bray F, Ferlay J, Soerjomataram I, et al. Global cancer statistics 2018: GLOBOCAN estimates of incidence and mortality worldwide for 36 cancers in 185 countries. CA-Cancer J Clin. 2018;68(6):394-424. https://doi.org/10. 3322/caac.21492.

2. Raihan R, Azzeri A, Shabaruddin HF, et al. Hepatocellular carcinoma in malaysia and its changing trend. Euroasian J Hepatogastroenterol. 2018;8(1):54-6. https://doi.org/10.5005/jp-journals-10018-1259.

3. Chen M, Therneau T, Orsini LS, et al. Design and rationale of the HCC BRIDGE study in China: a longitudinal, multicenter cohort trial in hepatocellular carcinoma. BMC Gastroenterol. 2011;11:53. https://doi.org/10. 1186/1471-230X-11-53.

4. Cheng AL, Kang YK, Chen Z, et al. Efficacy and safety of sorafenib in patients in the Asia-Pacific region with advanced hepatocellular carcinoma: a phase III randomised, double-blind, placebo-controlled trial. Lancet Oncol. 2009;10(1):25-34. https://doi.org/10.1016/S1470-2045(08) 70285-7.

5. Kudo M, Finn RS, Qin S, et al. Lenvatinib versus sorafenib in first-line treatment of patients with unresectable hepatocellular carcinoma: a randomised phase 3 non-inferiority trial. Lancet. 2018;391(10126):1163-73. https://doi.org/10.1016/S0140-6736(18)30207-1.

6. Bruix J, Qin S, Merle P, et al. Regorafenib for patients with hepatocellular carcinoma who progressed on sorafenib treatment (RESORCE): a randomised, double-blind, placebo-controlled, phase 3 trial. Lancet. 2017:389(10064):56-66. https://doi.org/10.1016/S0140-6736(16)32453-9.

7. Reig M, Bruix J. Lenvatinib: can a non-inferiority trial change clinical practice? Lancet. 2018;391(10126):1123-4. https://doi.org/10.1016/S01406736(18)30208-3.

8. Asakawa Y. Recent advances in phytochemistry of bryophytes-acetogenins, terpenoids and bis(bibenzyl)s from selected Japanese, Taiwanese, New Zealand, Argentinean and European liverworts. Phytochemistry. 2001;56(3):297-312. https://doi.org/10.1016/S0031-9422(00)00454-4.

9. Wu XZ, Cheng AX, Sun LM, et al. Effect of plagiochin $E$, an antifungal macrocyclic bis(bibenzyl), on cell wall chitin synthesis in Candida albicans. Acta Pharmacol Sin. 2008;29(12):1478-85. https://doi.org/10.1111/j.17457254.2008.00900.x. 
10. Linde J, Combrinck S, Vuuren SV, et al. Volatile constituents and antimicrobial activities of nine South African liverwort species. Phytochem Lett. 2016;16:61-9. https://doi.org/10.1016/j.phytol.2016.03.003.

11. Singh $M$, Singh $S$, Nath V, et al. Antibacterial activity of some bryophytes used traditionally for the treatment of burn infections. Pharm Biol. 2011;49(5):526-30. https://doi.org/10.3109/13880209.2010. 523007.

12. Asakawa Y, Ludwiczuk A, Nagashima F. Phytochemical and biological studies of bryophytes. Phytochemistry. 2013;91:52-80. https://doi.org/ 10.1016/j.phytochem.2012.04.012.

13. Li Y, Zhu R, Zhang J, et al. Clerodane diterpenoids from the Chinese liverwort Jamesoniella autumnalis and their anti-inflammatory activity. Phytochemistry. 2018;154:85-93. https://doi.org/10.1016/j.phytochem.

14. Tosun A, Akkol EK, Suntar I, et al. Phytochemical investigations and bioactivity evaluation of liverworts as a function of anti-inflammatory and antinociceptive properties in animal models. Pharm Biol. 2013;51 (8):1008-13. https://doi.org/10.3109/13880209.2013.774028.

15. Asakawa Y, Ludwiczuk A. Chemical constituents of bryophytes: structures and biological activity. J Nat Prod. 2018;81(3):641-60. https://doi. org/10.1021/acs.jnatprod.6b01046.

16. Gokbulut A, Satilmis B, Batcioglu K, et al. Antioxidant activity and luteolin content of Marchantia polymorpha L. Turk J Biol. 2012;36:381-5. https://doi.org/10.3906/biy-1106-15.

17. Niu C, Qu JB, Lou HX. Antifungal bis[bibenzyls] from the Chinese liverwort Marchantia polymorpha L. Chem Biodivers. 2006;3(1):34-40. https://doi.org/10.1002/cbdv.200690004.

18. Jensen JS, Omarsdottir S, Thorsteinsdottir JB, et al. Synergistic cytotoxic effect of the microtubule inhibitor marchantin A from marchantia polymorpha and the aurora kinase inhibitor MLN8237 on breast cancer cells in vitro. Planta Med. 2012;78(5):448-54. https://doi.org/10.1055/s0031-1298230.

19. Huang WJ, Wu CL, Lin CW, et al. Marchantin A, a cyclic bis(bibenzyl ether), isolated from the liverwort Marchantia emarginata subsp. tosana induces apoptosis in human MCF-7 breast cancer cells. Cancer Lett. 2010;291(1):108-19. https://doi.org/10.1016/j.canlet.2009.10.006.

20. Liu G, Zhang D, Yang J, et al. In vitro and in vivo evaluation of riccardin D nanosuspensions with different particle size. Colloids Surf B. 2013;102:620.

21. Yang Y, Yuan P, Wei X, et al. Cultivated and wild Pleurotus ferulae ethanol extracts inhibit hepatocellular carcinoma cell growth via inducing endoplasmic reticulum stress- and mitochondria-dependent apoptosis. Sci Rep. 2018;8(1):13984. https://doi.org/10.1038/ s41598-018-32225-4.

22. He J, Chen LD, Chu BQ, et al. Determination of total polysaccharides and total flavonoids in chrysanthemum morifolium using near-infrared hyperspectral imaging and multivariate analysis. Molecules. 2018;23(9):2395. https://doi.org/10.3390/molecules23092395.

23. Wei $X$, Xia L, Ziyayiding $D$, et al. The extracts of Artemisia absinthium $L$. suppress the growth of hepatocellular carcinoma cells through induction of apoptosis via endoplasmic reticulum stress and mitochondrialdependent pathway. Molecules. 2019;24(5):913. https://doi.org/10.3390/ molecules24050913.

24. Mishra R, Thorat D, Soundararajan G, et al. Semaphorin $3 A$ upregulates FOXO 3a-dependent MelCAM expression leading to attenuation of breast tumor growth and angiogenesis. Oncogene. 2015;34(12):1584-95. https://doi.org/10.1038/onc.2014.79.

25. Yu W, Zhang X, Liu J, et al. Cyclosporine a suppressed glucose oxidase induced P53 mitochondrial translocation and hepatic cell apoptosis through blocking mitochondrial permeability transition. Int J Biol Sci. 2016;12(2):198-209. https://doi.org/10.7150/ijbs.13716.

26. Gu S, Chen C, Jiang X, et al. ROS-mediated endoplasmic reticulum stress and mitochondrial dysfunction underlie apoptosis induced by resveratrol and arsenic trioxide in A549 cells. Chem Biol Interact. 2016;245:100-9. https://doi.org/10.1016/j.cbi.2016.01.005.

27. Lin T, Lee JE, Kang JW, et al. Endoplasmic reticulum (ER) stress and unfolded protein response (UPR) in Mammalian oocyte maturation and preimplantation embryo development. Int J Mol Sci. 2019;20(2):409. https://doi.org/10.3390/ijms20020409.

28. Huang F, Zhao J, Wei Y, et al. Anti-tumor efficacy of an adjuvant built-in nanovaccine based on ubiquitinated proteins from tumor cells. Int J Nanomed. 2020;15:1021-35. https://doi.org/10.2147/IJN.S237578.
29. Xu XH, Liu QY, LiT, et al. Garcinone E induces apoptosis and inhibits migration and invasion in ovarian cancer cells. Sci Rep. 2017;7(1):10718. https://doi.org/10.1038/s41598-017-11417-4.

30. Patil BR, Kang SY, Jung DH, et al. Design of a novel theranostic nanomedicine (III): synthesis and physicochemical properties of tumor-targeting cisplatin conjugated to a hydrophilic polyphosphazene. Int J Nanomed. 2020;15:981-90. https://doi.org/10.2147/IJN.S235618.

31. Schwiertz V, Bertin C, Henry A, et al. Estimation du nombre et de la nature des interactions médicamenteuses concernant les médicaments anticancéreux [Number and nature of drug interactions concerning antineoplastic drugs]. Bull Cancer. 2007;94(5):477-82.

32. Weiss JM, Davies $L C$, Karwan $M$, et al. Itaconic acid mediates crosstalk between macrophage metabolism and peritoneal tumors. J Clin Invest. 2018;128(9):3794-805. https://doi.org/10.1172/JCl99169.

33. Das UN. From bench to the clinic: gamma-linolenic acid therapy of human gliomas. Prostaglandins Leukot Essent Fatty Acids. 2004;70(6):539-52. https://doi.org/10.1016/j.plefa.2003.12.001.

34. Edin ML, Duval C, Zhang G, et al. Role of linoleic acid-derived oxylipins in cancer. Cancer Metastasis Rev. 2020;39(3):581-2. https://doi.org/10.1007/ s10555-020-09904-8.

35. Wang W, Yang J, Edin ML, et al. Targeted metabolomics identifies the cytochrome P450 monooxygenase eicosanoid pathway as a novel therapeutic target of colon tumorigenesis. Cancer Res. 2019;79(8):1822-30. https://doi.org/10.1158/0008-5472.CAN-18-3221.

36. Al Jawadi A, Rasha F, Ramalingam $L$, et al. Protective effects of eicosapentaenoic acid in adipocyte-breast cancer cell cross talk. J Nutr Biochem. 2020;75: 108244. https://doi.org/10.1016/j.jnutbio.2019.108244.

37. Maiti A, Cuendet M, Kondratyuk T, et al. Synthesis and cancer chemopreventive activity of zapotin, a natural product from Casimiroa edulis. J Med Chem. 2007;50(2):350-5. https://doi.org/10.1021/jm060915.

38. Galstyan A, Markman JL, Shatalova ES, et al. Blood-brain barrier permeable nano immunoconjugates induce local immune responses for glioma therapy. Nat Commun. 2020;11(1):6170. https://doi.org/10.1038/ s41467-019-11719-3.

39. Furth AM, Seijmonsbergen EM, Langermans JA, et al. Effect of xanthine derivates and dexamethasone on Streptococcus pneumoniae-stimulated production of tumor necrosis factor alpha, interleukin-1 beta (IL-1 beta), and IL-10 by human leukocytes. Clin Diagn Lab Immunol. 1995;2(6):68992. https://doi.org/10.1128/cdli.2.6.689-692.1995.

40. Burattini S, Salucci S, Baldassarri V, et al. Anti-apoptotic activity of hydroxytyrosol and hydroxytyrosyl laurate. Food Chem Toxicol. 2013;55:248-56. https://doi.org/10.1016/.jft.2012.12.049.

41. Chen YL, Hung HM, Lu CM, et al. Synthesis and anticancer evaluation of certain indolo[2,3-b]quinoline derivatives. Bioorg Med Chem. 2004;12(24):6539-46. https://doi.org/10.1016/j.bmc.2004.09.025.

42. Agapova LS, Chernyak BV, Domnina LV, et al. Mitochondria-targeted plastoquinone derivatives as tools to interrupt execution of the aging program. 3. Inhibitory effect of SkQ1 on tumor development from p53-deficient cells. Biochemistry (Mosc). 2008;73(12):1300-16. https://doi. org/10.1134/s0006297908120031.

43. Santos-Pirath IM, Walter LO, Maioral MF, et al. Apoptotic events induced by a natural plastoquinone from the marine alga Desmarestia menziesii in lymphoid neoplasms. Exp Hematol. 2020;86:67-77.e2. https://doi.org/10. 1016/j.exphem.2020.05.003.

44. Roy NK, Parama D, Banik K, et al. An update on pharmacological potential of Boswellic acids against chronic diseases. Int J Mol Sci. 2019;20(17):4101. https://doi.org/10.3390/ijms20174101.

45. Amen YM, Zhu Q, Tran HB, et al. Lucidumol C, a new cytotoxic lanostanoid triterpene from Ganoderma lingzhi against human cancer cells. J Nat Med. 2016;70(3):661-6. https://doi.org/10.1007/s11418-016-0976-2.

46. Li Z, Wang Y, Jiang B, et al. Structure, cytotoxic activity and mechanism of protoilludane sesquiterpene aryl esters from the mycelium of Armillaria mellea. J Ethnopharmacol. 2016;184:119-27. https://doi.org/10.1016/j.jep. 2016.02.044.

47. Rodriguez R, Hansen LT, Phear G, et al. Thymidine selectively enhances growth suppressive effects of camptothecin/irinotecan in MSI+ cells and tumors containing a mutation of MRE11. Clin Cancer Res. 2008;14(17):5476-83. https://doi.org/10.1158/1078-0432.CCR-08-0274.

48. He H, Feng YS, Zang LH, et al. Nitric oxide induces apoptosis and autophagy; autophagy down-regulates NO synthesis in 
physalin A-treated A375-\$2 human melanoma cells. Food Chem Toxicol. 2014;71:128-35. https://doi.org/10.1016/j.fct.2014.06.007.

49. Guo Y, Xu LS, Zhang D, et al. Betaine effects on morphology, proliferation, and p53-induced Apoptosis of HeLa cervical carcinoma cells in vitro. Asian Pac J Cancer Prevent. 2015;16(8):3195-201. https://doi.org/10.7314/ apjcp.2015.16.8.3195.

50. Nishio Y, Kakizoe T, Ohtani M, et al. L-isoleucine and L-leucine: tumor promoters of bladder cancer in rats. Science. 1986;231(4740):843-5. https:// doi.org/10.1515/cclm-2012-0689.

51. Spagnuolo C, Russo GL, Orhan IE, et al. Genistein and cancer: current status, challenges, and future directions. Adv Nutr. 2015;6(4):408-19. https:// doi.org/10.3945/an.114.008052

52. Zhang $X$, Wu Y, Li Z, et al. Glycodendron/pyropheophorbide-a (Ppa)functionalized hyaluronic acid as a nanosystem for tumor photodynamic therapy. Carbohydr Polym. 2020;247: 116749. https://doi.org/10.1016/j. carbpol.2020.116749.

53. Gelzo M, Granato G, Albano F, et al. Evaluation of cytotoxic effects of 7-dehydrocholesterol on melanoma cells. Free Radic Biol Med. 2014;70:129-40. https://doi.org/10.1016/j.freeradbiomed.2014.02.013.

54. Guo Z, Hu G, Wang H, et al. Ampelopsin inhibits human glioma through inducing apoptosis and autophagy dependent on ROS generation and JNK pathway. Biomed Pharmacother. 2019;116:108524. https://doi.org/ 10.1016/j.biopha.2018.12.136.

55. Bulaj G, Margaret M, Alexis K, et al. Incorporating natural products, pharmaceutical drugs, self-care and digital/mobile health technologies into molecular-behavioral combination therapies for chronic diseases. Curr Clin Pharmacol. 2016;11(2):128-45. https://doi.org/10.2174/1574884711 666160603012237

56. Yuan P, Li J, Aipire A, et al. Cistanche tubulosa phenylethanoid glycosides induce apoptosis in $\mathrm{H} 22$ hepatocellular carcinoma cells through both extrinsic and intrinsic signaling pathways. BMC Complement Altern Med. 2018;18(1):275. https://doi.org/10.1186/s12906-018-2201-1

57. Yuan $W$, Cheng $X$, Wang $P$, et al. Polytrichum commune L.ex Hedw ethyl acetate extract-triggered perturbations in intracellular $\mathrm{Ca}^{2+}$ homeostasis regulates mitochondrial-dependent apoptosis. J Ethnopharmacol. 2015;172:410-20. https://doi.org/10.1016/j.jep.2015.07.002.

58. Li JP, Yang YX, Liu QL, et al. The investigational Aurora kinase A inhibitor alisertib (MLN8237) induces cell cycle G2/M arrest, apoptosis, and autophagy via p38 MAPK and Akt/mTOR signaling pathways in human breast cancer cells. Drug Drug Des Devel Ther. 2015;9:1627-52. https:// doi.org/10.2147/DDDT.S75378.

59. Lin WR, Lai MW, Yeh CT. Cyclin-dependent kinase-associated protein phosphatase is overexpressed in alcohol-related hepatocellular carcinoma and influences xenograft tumor growth. Oncol Rep. 2013;29(3):903-10. https://doi.org/10.3892/or.2012.2208.

60. Wang D, Sun $Q$, Wu J, et al. A new prenylated flavonoid induces G0/G1 arrest and apoptosis through p38/JNK MAPK pathways in human hepatocellular carcinoma cells. Sci Rep. 2017;7(1):5736. https://doi.org/10.1038/ s41598-017-05955-0.

61. Shi XN, Li HJ, Yao H, et al. In silico identification and in vitro and in vivo validation of anti-psychotic drug fluspirilene as a potential CDK2 inhibitor and a candidate anti-cancer drug. PLOS ONE. 2015;10(7): e0132072. https://doi.org/10.1371/journal.pone.0132072.

62. Hanse EA, Nelsen CJ, Goggin MM, et al. Cdk2 plays a critical role in hepatocyte cell cycle progression and survival in the setting of cyclin D1 expression in vivo. Cell Cycle. 2009;8(17):2802-9. https://doi.org/10.4161/ cc.8.17.9465.

63. Hara M, Abe Y, Tanaka T, et al. Greatwall kinase and cyclin B-Cdk1 are both critical constituents of M-phase-promoting factor. Nat Commun. 2012;3:1059. https://doi.org/10.1038/ncomms2062.

64. Jones MC, Askari JA, Humphries JD, Humphries MJ. Cell adhesion is regulated by CDK1 during the cell cycle. J Cell Biol. 2018;217(9):3203-18. https://doi.org/10.1083/jcb.201802088.
65. Sur S, Agrawal DK. Phosphatases and kinases regulating CDC25 activity in the cell cycle: clinical implications of CDC25 overexpression and potential treatment strategies. Mol Cell Biochem. 2016;416(1-2):33-46. https://doi. org/10.1007/s11010-016-2693-2.

66. Liu Z, Li J, Chen J, et al. MCM family in HCC: MCM6 indicates adverse tumor features and poor outcomes and promotes S/G2 cell cycle progression. BMC Cancer. 2018;18(1):200. https://doi.org/10.1186/ s12885-018-4056-8.

67. Fusté NP, Fernández-Hernández R, Cemeli T, et al. Cytoplasmic cyclin D1 regulates cell invasion and metastasis through the phosphorylation of paxillin. Nat Commun. 2016;7:11581. https://doi.org/10.1038/ncomm s11581.

68. Saneesh Babu PS, Manu PM, Dhanya TJ, et al. Bis(3,5-diiodo-2,4,6-trihydroxyphenyl)squaraine photodynamic therapy disrupts redox homeostasis and induce mitochondria-mediated apoptosis in human breast cancer cells. Sci Rep. 2017;7:42126. https://doi.org/10.1038/srep42126.

69. Denning DP, Hatch V, Horvitz HR. Both the caspase CSP-1 and a caspaseindependent pathway promote programmed cell death in parallel to the canonical pathway for apoptosis in Caenorhabditis elegans. PLoS Genet. 2013;9(3): e1003341. https://doi.org/10.1371/journal.pgen.1003341.

70. Yuan J, Najafov A, Py BF. Roles of caspases in necrotic cell death. Cell. 2016;167(7):1693-704. https://doi.org/10.1016/j.cell.2016.11.047.

71. Knight T, Luedtke $D$, Edwards $H$, et al. A delicate balance- the BCL-2 family and its role in apoptosis, oncogenesis, and cancer therapeutics. Biochem Pharmacol. 2019;162:250-61. https://doi.org/10.1016/j.bcp.2019.01.015.

72. Butler MR, Ma H, Yang F, et al. Endoplasmic reticulum (ER) $\mathrm{Ca}^{2+}$-channel activity contributes to ER stress and cone death in cyclic nucleotidegated channel deficiency. J Biol Chem. 2017;292(27):11189-205. https:// doi.org/10.1074/jbc.M117.782326.

73. Yoo YS, Han HG, Jeon YJ. Unfolded protein response of the endoplasmic reticulum in tumor progression and immunogenicity. Oxid Med Cell Longev. 2017;2017:1. https://doi.org/10.1155/2017/2969271.

74. Cubillos-Ruiz JR, Bettigole SE, Glimcher LH. Tumorigenic and immunosuppressive effects of endoplasmic reticulum stress in cancer. Cell. 2017;168(4):692-706. https://doi.org/10.1016/j.cell.2016.12.004.

75. Kanda S, Yanagitani K, Yokota Y, et al. Autonomous translational pausing is required for XBP1 $\mathrm{U}$ mRNA recruitment to the ER via the SRP pathway. Proc Natl Acad Sci USA. 2016;113(40):E5886-95. https://doi.org/10.1073/ pnas. 1604435113.

76. Siwecka N, Rozpędek W, Pytel D, et al. Dual role of endoplasmic reticulum stress-mediated unfolded protein response signaling pathway in carcinogenesis. Int J Mol Sci. 2019;20(18):4354. https://doi.org/10.3390/ijms2 0184354.

77. Rozpędek W, Pytel D, Mucha B, et al. The role of the PERK/elF2a/ATF4/ CHOP signaling pathway in tumor progression during endoplasmic reticulum stress. Curr Mol Med. 2016;16(6):533-44. https://doi.org/10. 2174/1566524016666160523143937.

78. Holczer M, Bánhegyi G, Kapuy O. GADD34 keeps the mTOR pathway inactivated in endoplasmic reticulum stress related autophagy. PLoS ONE. 2016;11(12): e0168359. https://doi.org/10.1371/journal.pone.0168359.

79. Galluzzi L, Senovilla L, Vitale I, et al. Molecular mechanisms of cisplatin resistance. Oncogene. 2012;31(15):1869. https://doi.org/10.1038/onc. 2011.384 (Epub 2011 Sep 5).

80. Qi L, Luo Q, Zhang Y, et al. Advances in toxicological research of the anticancer drug cisplatin. Chem Res Toxicol. 2019;32(8):1469. https://doi. org/10.1021/acs.chemrestox.9b00204 (Epub 2019 Aug 5).

\section{Publisher's Note}

Springer Nature remains neutral with regard to jurisdictional claims in published maps and institutional affiliations. 